\title{
LA ACTIVIDAD ALFARERA EN LA CIUDAD DE LEÓN DURANTE LOS SIGLOS MEDIEVALES ${ }^{1}$
}

\author{
POTTERY ACTIVITY IN THE CITY OF LEÓN \\ DURING THE MEDIEVAL PERIOD
}

\author{
RAQUEL MARTÍNEZ PEÑÍN \\ Universidad de León
}

\begin{abstract}
Resumen: Este trabajo trata de ofrecer una visión multifocal y evolutiva sobre el desarrollo de la actividad alfarera en la ciudad de León y su alfoz durante los siglos medievales. El objetivo es analizar las características de la producción a lo largo del período acotado, estudiando los cambios y las pervivencias. Para tal fin contamos con un triple soporte informativo: en primer lugar, las referencias documentales, no sólo de época medieval sino también de comienzos de la Edad Moderna. En segundo, la información emanada de las recientes intervenciones arqueológicas desarrolladas en distintos solares de la urbe y de su entorno más inmediato. Y, finalmente, sobre todo para el análisis de la evolución tecnológica, los datos proporcionados por los diferentes análisis macro y microscópicos realizados a una serie de recipientes cerámicos exhumados en diversos contextos arqueológicos que cuentan con secuencias estratigráficas aclaratorias.
\end{abstract}

Palabras clave: cerámica; producción; alfarería; León; Edad Media.

\begin{abstract}
This work aims to provide a multifocal and progressive view of the development of pottery making in the city of León and its outskirts during the Middle Ages. The objective is to analyze the characteristics of the production over the period in question, studying the changes and the survivals. To this end we are aided by a threefold supply of information: first, the documentary references, not only from medieval times but also the beginning of the Modern Age. Second, the information coming from the recent archaeological work carried out at various sites in the city and its immediate surroundings. And finally, especially for the analysis of technological evolution, the data provided by the different macroand microscopic analyses performed on a series of ceramic vessels unearthed at various archaeological contexts with clarificatory stratigraphic sequences.
\end{abstract}

Keywords: pottery; production; pottery workshop; León; Middle Ages.

\section{SUMARIO}

1. El punto de partida: las fuentes para el estudio de la actividad alfarera en el León medieval.2. Marco espacial y temporal: la evolución urbana de León durante la Edad Media.- 3. La actividad alfarera leonesa en la ciudad de León y su alfoz.- 4. Conclusiones.- 5. Bibliografía citada.

${ }^{1}$ Abreviaturas utilizadas: AGS $=$ Archivo General de Simancas; AHML $=$ Archivo Histórico Municipal de León; AHPL = Archivo Histórico Provincial de León; ARCHV = Archivo de la Real Chancillería de Valladolid; $\mathrm{CCL}=$ Colección documental de la Catedral de León, CDS = Colección documental del Monasterio de Sahagún; CSIL = Colección documental de San Isidoro de León. 


\section{EL PUNTO DE PARTIDA: \\ LAS FUENTES PARA EL ESTUDIO DE LA ACTIVIDAD ALFARERA EN EL LEÓN MEDIEVAL}

La escasez de información documental sobre la actividad alfarera en el Medievo es algo relativamente frecuente a nivel peninsular. Es la razón que explica la limitada proliferación de estudios sobre este sector artesanal en comparación con otros que gozan de una mayor presencia en las fuentes ${ }^{2}$. No deja de resultar un tanto paradójico el contraste existente entre ese raquitismo informativo y la abundancia de los restos cerámicos en las intervenciones arqueológicas practicadas en contextos medievales. Autores como Boüard ${ }^{3}$ o Córdoba de la Llave ${ }^{4}$ relacionan la escasa presencia de los alfareros en la documentación manuscrita con la discreta relevancia económica de este sector artesanal. Desde luego, no hay duda de que así sucedía también en León, como se evidencia en el hecho de que en las ordenanzas concejiles de comienzos de la Edad Moderna ni siquiera se encuentre regulada su actividad, a diferencia de lo que sucede con otras agrupaciones de artesanos, caso de los tejedores, sastres, curtidores, zapateros o cereros ${ }^{5}$. Además, junto a la escasa relevancia económica de los olleros leoneses, también su reducido número y las limitadas dimensiones de la ciudad en donde operaban ayudan a explicar esta escasez de información. Es evidente que no podemos pretender contar con un abanico documental tan extenso para León como para los centros urbanos mediterráneos o del entorno andaluz. No olvidemos que, a finales del siglo XVI la capital norteña no alcanzaba los 4.000 habitantes $^{6}$; nada que ver, pues con urbes como Barcelona o Córdoba ${ }^{7}$, que cuentan con estudios de estas características. Sin olvidar el hecho de que aquellas ciudades eran importantes centros de producción, circunstancia que no se daba en el caso leonés.

En consecuencia, nosotros no disfrutaremos en nuestro análisis de la riqueza informativa hallada por Padilla Lapuente y Vila i Carabasa ${ }^{8}$, cuando acometieron

\footnotetext{
${ }^{2}$ Desde el punto de vista documental, el mundo artesanal medieval cuenta con abundantes estudios para el ámbito hispano, en especial referidos al sector textil. Sirvan como ejemplo, entre otros, los siguientes trabajos: D. Igual, Comercio, pp. 373-394; G. Navarro, La industria textil, pp. 673-705; M. Diago, La industria y el comercio; H. R. Oliva, La industria textil, pp. 225-251; R. Córdoba, La industria medieval; R. Córdoba, Las técnicas preindustriales, t. II, pp. 334-382.

${ }^{3}$ M. Boüard, I. Ollich, M. Riu, Manual de Arqueología Medieval.

${ }^{4}$ Especialmente en su obra R. Córdoba, La industria medieval.

${ }^{5}$ L.M. Rubio, Ordenanzas de León; P. Marcos, Legalidad y realidad, pp. 135-168.

${ }^{6}$ Según las estimaciones realizadas sobre el censo de Tomás González (1591), la población ascendería a unos 3.846 habitantes; M.J. Pérez, Mortalité et hygiène, pp. 55-79.

${ }^{7}$ No es posible desarrollar en los limitados márgenes de este estudio un análisis pormenorizado de la producción científica referida a les alfares medievales y modernos. Nos limitamos pues a esbozar algunas pinceladas. Así, podemos destacar, para el ámbito aragonés los siguientes estudios: M. Almagro, L. Llubiá, La cerámica; Y. Álvarez, Excavación, t. IV, pp. 615-638; M.I. Álvaro, Cerámica aragonesa; M.I. Álvaro, La cerámica aragonesa, pp. 91-152; P. Atrián, Hallazgo, pp. 23-25; C. Escó, Alfares, pp. 169-196; J. Ortega, Cerámica y feudalismo, pp. 111-141; J. Ortega, El contexto historiográfico, pp. 79-110; J. Ortega, Operis Terra Turolii; J. Ortega, F.J. Gutiérrez, La cerámica medieval, pp. 397-421.

En cuanto a las producciones valencianas, podemos mencionar publicaciones como las siguientes: F. Amigues, Premières, pp. 27-64; F. Amigues, La cerámica valenciana, pp. 69-87; F. Amigues, M. Mesqueda, Tradición alfarera, pp. 143-155; F. Amigues, M. Mesqueda, La céramique de Paterna; M. Mesqueda, Una terrisseria; M. Mesqueda, Alfareros; M. Mesqueda, La cerámica de Paterna; M. Mesqueda, La cocción de cerámica, pp. 121-138; M. Mesqueda, La cerámica azul, pp. 97-107; J. Molera, M. Vendrell, Caracterización tecnológica de las cerámicas.

8 J.I. Padilla, J.M. Vila, Els oficis terrissers, pp. 63-70; J.I. Padilla, J.M Vila, El artesanado, pp. 249-261; J.M Vila, J.I. Padilla, J. Hernando, Cerámica, pp. 559-562; J.I. Padilla, J.M Vila, Úl-
} 
el vaciado sistemático de las fuentes manuscritas sobre este sector en la capital catalana ${ }^{9}$. En aquel caso, los autores localizaron referencias directas a alfareros o a sus actividades en un amplio abanico de documentación: desde las ordenanzas municipales, hasta los estatutos de algunas cofradías, pasando por un número significativo de escrituras notariales -convenios, compañías, testamentos, inventarios-, o incluso por la documentación privada, sin olvidarnos de otras fuentes de carácter indirecto, caso de la toponimia urbana, la documentación fiscal, etc. Esta línea abierta, fue continuada años más tarde por los trabajos de Riu de Martín, que extendía su visión más allá del Medievo, y que manejaba, entre otros instrumentos de información, tanto los inventarios como las subastas de bienes de los ceramistas y vidrieros barceloneses de entre los siglos XV y XVII ${ }^{10}$.

Estas circunstancias, más o menos propicias, se repiten a su vez en el caso cordobés, analizado por Córdoba de la Llave. El autor, amén de emplear como referencia la toponimia fosilizada, halla información sobre el oficio alfarero tanto en las ordenanzas municipales, como en distintos contratos. Dichas fuentes ofrecen una visión íntegra del desarrollo de la actividad ollera en la Córdoba bajomedieval. Así, se describen buena parte de los pasos que llevan a cabo en el proceso de elaboración de los recipientes, desde la preparación de los barros hasta el modelado y vidriado de las piezas ${ }^{11}$.

En consecuencia, las referencias documentales sobre las actividades alfareras del entorno leonés son, incluso, menos frecuentes que las halladas para los contextos mejor estudiados hasta el momento, algo, como ya señalamos, nada extraño, teniendo en cuenta las dimensiones poblacionales de la ciudad y su relevancia económica. Precisamente por ello, su recopilación y contraste con los datos arqueológicos o con otros instrumentos de información, caso por ejemplo de la toponimia, resultan todavía más necesarios. Ese será, pues, nuestro objetivo, tomando como referencia metodológica los estudios anteriormente reseñados ${ }^{12}$.

\section{MARCO ESPACIAL Y TEMPORAL: LA EVOLUCIÓN URBANA DE LEÓN DURANTE LA EDAD MEDIA}

Como es sabido, los orígenes de León se remontan a la época augusta, cuando se establece en aquel ámbito el primer acuartelamiento de la legio VI Victrix, el

timas intervenciones en el alfar, pp. 91-99; J.I. Padilla, J.M Vila, El tester 347-B de Cabrera d'Anoia, pp. 143-158; J.M Vila, Política municipal, pp. 104-126; J. I. Padilla, Adaptación al medio, pp. 259-294.

${ }_{9}$ Estos trabajos tuvieron como antecedente, los desarrollados por el francés Bonnassie o el catalán Albertí, si bien éstos eran de carácter más general. P. Bonnassie, La organización del trabajo; S. Albertí, Notes sobre els rajolers, pp. 11-17; S. Albertí, El llibre d'ordinacions gremials, pp. 22-26; S. Albertí, Els origens gremials, pp. 32-35.

${ }^{10} \mathrm{M}^{\mathrm{a}}$.C. Riu, El treball artesà, pp. 9-19; Ma.C. Riu, Vida cotidiana de los ceramistas, pp. $307-$ 355; Ma.C. Riu, Ceramistas barceloneses, pp. 191-206; Mª.C. Riu, Algunos aspectos de la producción, t. I, pp. 135-140.

${ }^{11}$ R. Córdoba, Alfares, pp. 195-202; R. Córdoba, La industria medieval; R. Córdoba, Innovación técnica, pp. 217-246; R. Córdoba, Las técnicas preindustriales, t. II, pp. 334-382. Asimismo, no queremos olvidar el exhaustivo análisis que Roselló Bordoy hace en su obra El ajuar de las casas andalusíes, en la que, combinando los datos aportados tanto por la documentación como por las evidencias materiales, recoge los distintos objetos del ámbito doméstico localizados en las casas andalusíes -cocina, almacenamiento, iluminación, etc.

12 J.I. Padilla, J.M. Vila, Últimas intervenciones en el alfar, pp. 91-99; R. Córdoba, La industria medieval; M ${ }^{\mathrm{a}}$.C. Riu, Ceramistas barceloneses, pp. 191-206; Mª.C. Riu, Algunos aspectos de la producción, t. I, pp. 135-140. 
cual permanecerá en la Península Ibérica hasta aproximadamente el año 69-70 d C $\mathrm{C}^{13}$. Más tarde, tras la marcha de este contingente militar, en torno al año 74, tiene lugar el asentamiento de la legio VII Gemina, donde permanece al menos hasta el siglo IV.

En época bajoimperial, el declive y proceso de ruralización que se extiende por el Occidente romano, trae consigo que el protagonismo administrativo y económico se traslade desde Legio al campo, extendiéndose así los asentamientos en villas como modelo de explotación y hábitat. Estos enclaves pues se convertirán en zonas de atracción para nuevos pobladores ${ }^{14}$. En las últimas décadas del siglo III o comienzos del IV Legio se rodea de una nueva muralla que se adosa a la construida en época alto imperial por su cara externa ${ }^{15}$. Durante este periodo se evidencia una escasa densidad de población y la reutilización de espacios preexistentes, algo que se mantiene durante el periodo hispano-visigodo.

Lo cierto es que, las fuentes manuscritas que aluden a Legio son más bien pobres, algo bastante común para este momento histórico. Aún así, contamos con datos como los recogidos en el Parroquial Suevo o Divisio Theodomiri ${ }^{16}$, donde se menciona a León como una de las diez parroquias que constituían la diócesis de Asturica Augusta. Para estos momentos, se considera que los núcleos que cuentan con la categoría de sede episcopal son los únicos que se articularían como auténticas civitas, por lo que Legio no adquirirá tal rango hasta los tiempos de Alfonso III (848-910) ${ }^{17}$.

Tampoco durante la Alta Edad Media, podemos hablar de una civitas propiamente dicha, sino más bien de un núcleo pre-urbano, poco poblado, que empieza a experimentar ciertas transformaciones a comienzos del siglo $\mathrm{X}$, con el traslado de la capital del reino astur-leonés desde Oviedo. A través de los dominios existentes en la urbe y su entorno, se va produciendo una progresiva concentración de las explotaciones agrarias, dentro y fuera del recinto campamental, a manos de los poderes regio y eclesiástico. Entre los siglos X y XI se evidencia un cierto crecimiento económico que afecta a todos los sectores y cuya manifestación más importante es la expansión del espacio agrícola. Esta positiva coyuntura se ha relacionado con un incremento de los efectivos demográficos, que a su vez impulsará el crecimiento de la producción de determinados artículos -textiles, aperos de labranza, etc.-, así como una cierta densificación en las construcciones. De hecho, en este momento cuando surgen las primeras referencias al mercado legionense ${ }^{18}$.

Durante la Plena Edad Media continúa la concentración de la propiedad en manos de la monarquía -realengo e Infantazgo- y la Iglesia. En esos momentos, se documenta un importante avance en los sistemas de cultivo, que conocemos sobre todo a través del Fuero de León, así como una intensificación de las explotaciones agrícolas ${ }^{19}$.

Aunque el crecimiento económico que experimenta la ciudad y su alfoz se base fundamentalmente en el desarrollo agrícola y ganadero, arrastraría también

\footnotetext{
13 Á. Morillo, Los campamentos romanos, pp. 83-110; V. García, Los campamentos de las legiones, pp. 167-198; Mª.L. González, Julio Vidal, Recientes hallazgos sobre el campamento de la legio VII, pp. 161-184.

${ }^{14}$ J. Arce, La trasformación de Hispania, pp. 227-249; J. López, Entre la "villa” y la "aldea”, pp. $19-60$.

15 J.A. Gutiérrez, Las fuentes arqueológicas, pp. 77-145.

${ }^{16}$ P. Díaz, El Parrochiale, pp. 35-48.

17 D. Mansilla, Panorama, p. 21; I. Bango, Alta Edad Media; I. Bango, Catedral de León, pp. 45-57; M. Valdés, C. Cosmen, Mª V. Herráez, Una historia arquitectónica.

${ }^{18}$ C. Estepa, Estructura social, pp. 415-432; C. Álvarez, La Historia de León, vol. II; J.A. Gutiérrez, Las fuentes arqueológicas, pp. 77-145; C. Estepa, La ciudad de León, pp. 12-27.

${ }^{19}$ C. Estepa, León en los siglos, vol. II, pp. 557-620; C. Álvarez, La Historia de León, pp. 54-57.
} 
consigo a otros sectores productivos, como el comercial y el artesanal. Estos se concentran fundamentalmente en torno a las parroquias de San Marcelo y San Martín, emplazadas ambas extramuros. La compraventa de productos agrícolas y artesanales provocó que se estrecharan las relaciones entre el campo y la ciudad, lo que trajo consigo el despegue de las ferias y mercados. Se produce así una cierta especialización económica, sobre todo relacionada con la producción alimentaria, la construcción, el trabajo textil o de los metales. También debemos relacionar el crecimiento económico experimentado en estas fechas con el despegue del Camino de Santiago, sobre todo a partir de la segunda mitad del siglo XI en adelante ${ }^{20}$.

Los inicios de la Baja Edad Media coinciden con las obras de construcción de la catedral gótica, manifestación clara del papel protagonista que, en detrimento de una autoridad regia ausente, ejercieron el cabildo catedralicio y los obispos a lo largo de este periodo ${ }^{21}$. En estos momentos, la ciudad experimenta un cierto crecimiento demográfico que tiene consecuencias en la configuración de su trama urbanística y que se sostiene en una prosperidad económica, heredera de momentos anteriores. De hecho, la documentación de la época refleja un sustancial incremento en las referencias a mercaderes, así como una mayor diversificación de oficios artesanales que evidencian esa coyuntura positiva. Así, además de los mercados permanente y semanal, comienzan a celebrarse dos ferias anuales de aproximadamente un mes de duración ${ }^{22}$.

A finales del siglo XIII y comienzos del XIV, la presión demográfica sobre el área meridional de la urbe hace necesaria la construcción de la Nueva Cerca, cerrando así una superficie de unas 15 ha. A partir de entonces, tanto la parroquia de San Martín como la de San Marcelo quedan incluidas en el interior del recinto amurallado. Esta última se convirtió en el centro político de la ciudad, como lugar de reunión de la autoridad concejil, si bien mantendrá también un importante núcleo de población dedicada a distintas labores artesanales. De hecho, la documentación medieval sitúa en este espacio un "Postigo de Ollerías", al que nos referiremos más adelante.

\section{LA ACTIVIDAD ALFARERA LEONESA EN LA CIUDAD DE LEÓN Y SU ALFOZ}

Nuestro conocimiento del sector alfarero leonés se va incrementando a medida que avanzan los siglos, siendo pues más profundo para la etapa bajomedieval que para la Alta Edad Media. Por otro lado, y con el fin de acentuar nuestra visión de conjunto, hemos optado por ampliar nuestra búsqueda documental más allá del Medievo. La existencia de información sumamente interesante para comienzos del periodo Moderno nos ha llevado a tomar esa decisión, habida cuenta de las escasas transformaciones que pudieron existir en las estructuras demográficas, sociales, económicas o culturales entre el León del siglo XV y el del XVI. Incluso, no deja de resultar esclarecedor conocer las características internas del sector objeto de estudio para toda la Edad Moderna, a la hora de entender, en su justa medida, el peso numérico e incluso económico desempeñado por los olleros bajomedievales.

Una vez realizadas estas necesarias puntualizaciones podemos ya acometer el análisis evolutivo del sector, comenzando por el mundo altomedieval. Para

${ }^{20}$ G. Cavero, Camino de Santiago, p. 101; Ma.D. Campos, M‥L. Pereiras, Iglesia, pp. 19-30.

${ }^{21}$ M. Valdés, $\mathrm{M}^{\mathrm{a}}$.V. Herráez, C. Cosmen, El arte gótico; E. Carrero, La arquitectura medieval, pp. 61-98.

${ }^{22}$ C. Álvarez, La ciudad de León, pp. 65-73; C. Álvarez, La Historia de León, vol. II, pp. 357-359. 
esta dilatada etapa contamos con datos documentales excesivamente puntuales y ambiguos, así como con una información arqueológica, hasta el momento, también demasiado parca. Como ya hemos puesto de manifiesto anteriormente, León comienza a fraguarse como un centro urbano a partir de su conversión en capital del reino en los inicios del siglo $\mathrm{X}$, si bien este proceso será lento, caracterizándose pues durante buena parte de este período por su escaso dinamismo demográfico y económico.

No contamos con referencias documentales de la actividad alfarera en estos momentos para la urbe. En cuanto a la información arqueológica, solamente disponemos de un trabajo de mediados de la década de los noventa del siglo pasado, fruto de las intervenciones desarrolladas en el entorno de la Puerta Castillo, en el que se hace referencia a la posible existencia en la zona de un alfar $^{23}$.

En lo que se refiere al alfoz legionense, las fuentes documentales nos ofrecen algunos datos de carácter toponímico, que nos remiten a la presumible existencia de una producción alfarera un tanto dispersa a lo largo y ancho de aquel territorio, tal y como había apuntado en su momento Estepa Díez ${ }^{24}$. Así, en la colección diplomática del monasterio de Sahagún se hace referencia a la localidad de Torneros de illa Regina ${ }^{25}$, población próxima, no sólo a la capital, sino también a algunos otros de los contextos arqueológicos donde se han exhumado cerámicas de este período, caso del Castro de los Judíos o de Marialba de la Ribera ${ }^{26}$. Las características de las producciones allí halladas se corresponden con las recogidas en las prospecciones arqueológicas de enclaves como el de Ardón y Santa Marta, también ubicadas en el propio alfoz ${ }^{27}$.

Asimismo, en la documentación catedralicia de León de los siglos X y XI, aparecen otras localidades que sugieren la existencia de actividades relacionadas con la fabricación de cerámica. Es el caso de Torneros del Bernesga o de la uilla de Ollarios $^{28}$ la población de Olleros de Alba, citada en un documento del año $1006^{29}$, o la localidad de Nava de Olleros, citada en varios documentos de comienzos del $\mathrm{XI}^{30}$.

En cuanto al material ceramológico propiamente dicho, las producciones de la Alta Edad Media corresponden a las comúnmente conocidas como cerámicas gris leonesa. Las observaciones macro y microscópicas nos han permitido identificar arcillas silíceas poco decantadas, de color gris, textura porosa y dura. En ellas se observan inclusiones de tipo mineral -cuarzo, espinela,...- bastante homogéneas, a base de partículas de entre 0,25 y $0,5 \mathrm{~mm}$.

${ }^{23}$ J.A. Gutiérrez, C. Benéitez, Cerámica medieval en León, pp. 211-260; J.A. Gutiérrez, Nuevos desarrollos en el estudio de las cerámicas, pp. 69-87.

${ }^{24}$ C. Estepa, Estructura social, pp. 373-412.

${ }^{25}$ CDS, núm. 355; J.M. Mínguez, Colección Diplomática.

${ }^{26}$ R. Martínez, Estudio de la cerámica; R. Martínez, El mobiliario cerámico.

27 También encontramos otras referencias al topónimo "torneros" en la documentación catedralicia entre los años 975 y 1045 (CCL, núm. 438, 549-550, 555, 564, 705, 770, 881, 884, 911 y 1.049).

${ }^{28}$ Este topónimo aparece reflejado en una serie de documentos de la Catedral de León (CCL, núm. $301,805,1.307,1.427$ y 1.749$)$.

${ }^{29}$ CCL, núm. 664; J.M. Ruíz, Colección Documental, III.

${ }^{30}$ CCL, núm. 809, 996, 1.089 y 1.326; J.M. Ruíz, Colección Documental, III; J.M. Ruíz, Colección Documental, IV. 


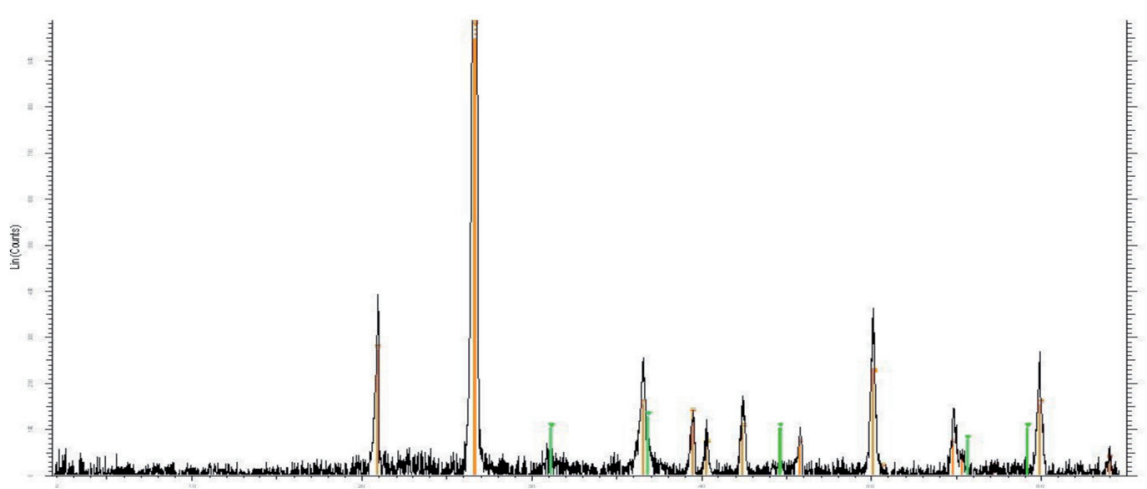

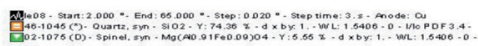

2.Theta. - soate

Fig. 1. Análisis mineralógico practicado a un fragmento de cerámica altomedieval.

En relación con el segundo de los minerales señalados, las muestras analizadas mediante difracción de rayos $\mathrm{X}$ han constatado que esa vajilla había sido sometida a altas temperaturas de cocción, pero inferiores a los $900-1000^{\circ} \mathrm{C}$. Tecnológicamente los recipientes se modelan combinando la torneta con el urdido y cuentan con un marcado carácter local, además de un reducido ámbito de distribución que se circunscribe a la ciudad de León y su entorno más próximo.

Tipológicamente se identifica un reducido repertorio formal, pudiendo hablar en general de piezas destinadas al fuego, caso de las ollas, jarras, jarros, cazuelas, cuencos, platos, candiles, fuentes, queseras, tapaderas, tinajas o piezas discoidales.

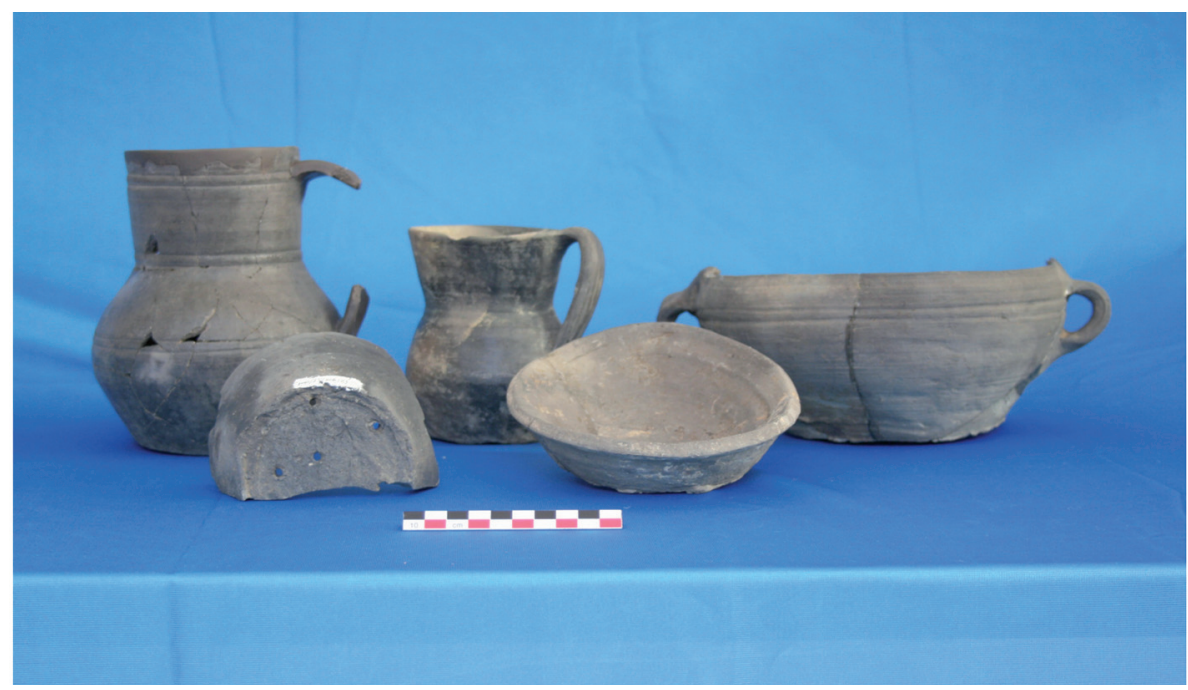

Fig. 2. Recipientes de cerámica altomedieval. 
Además, el acabado más frecuente entre éstas es el bruñido -vertical, horizontal o en zig-zag-, las incisiones a peine lineales, los cordones aplicados y las molduras. Desde una perspectiva morfológica y ornamental, hay que tener en cuenta que estas piezas muestran evidentes conexiones con las producciones hispano-visigodas, aunque presentan un aspecto todavía más tosco.

Este tipo de recipientes suele estar presente en los registros más antiguos de algunos de los enclaves altomedievales leoneses situados tanto al interior del recinto amurallado de la ciudad (la iglesia palatina de San Salvador de Palat de Rey, el $n^{\circ} 7$ de San Pelayo, el solar $n^{\circ} 8$ de la calle Sierra Pambley o en Puerta Obispo ${ }^{31}$ ) como fuera de la misma (la iglesia de Marialba de la Ribera o la judería de Puente Castro) $(\text { Tabla } 1)^{32}$.

Tabla 1. Tipología de la producción cerámica altomedieval.

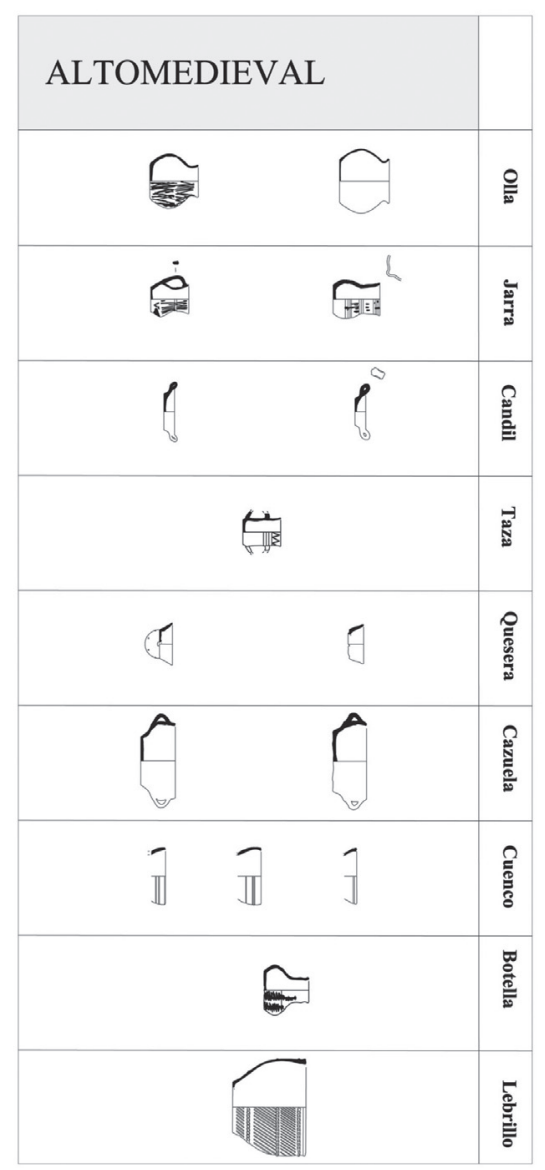

${ }^{31}$ J.A. Gutiérrez, F. Miguel, Las cerámicas altomedievales, t. I, pp. 447-461.

${ }^{32} \mathrm{R}$. Martínez, Análisis de la producción y distribución de la cerámica. 
Tomando todos estos datos esporádicos, podemos aventurarnos a sugerir algunas hipótesis sobre la posible actividad desarrollada por estos centros durante el Altomedievo. En primer lugar, la relativa proximidad cronológica de las referencias documentales, nos remiten a la posibilidad de la existencia de varios focos productores en el alfoz leonés, no muy alejados espacialmente unos de otros, que estarían conviviendo al mismo tiempo. Cada uno de ellos contaría con un área de distribución, mayor o menor dependiendo de su capacidad, que le posibilitaría la comercialización de sus productos. A este respecto, las principales vías de comunicación existentes en la época jugarían un destacado papel como vertebradoras del mercado local ${ }^{33}$, garantizando la salida de su modesta producción ${ }^{34}$.

Más abundante es la información de la que disponemos para los siglos de la Plena Edad Media. Recordamos que durante esta etapa la ciudad de León estaba viviendo un proceso de expansión demográfica y económica que, lógicamente, tendrá su repercusión en la actividad alfarera. El fortalecimiento de la urbe como sede regia, la consolidación del Camino Francés y la coyuntura agraria positiva, tiró del desarrollo comercial y artesanal de la capital. En este contexto, la demanda de productos cerámicos debió de crecer, como queda de manifiesto en el mayor número de referencias documentales sobre integrantes del sector alfarero para la época. Tal impresión se corrobora con el marcado incremento de restos cerámicos asociados a contextos de esta cronología. Ese apreciable aumento de fragmentos puede entenderse como una consecuencia del crecimiento en la producción alfarera.

Las cerámicas de cronología plenomedieval, evidencian una notable evolución desde el punto de vista técnico en comparación con las anteriores. Se realizan también con rocas silíceas, de colores variados, que pueden oscilar entre el blanco-amarillento y el marrón oscuro, pasando por diversas gamas de tonos rojizos y de textura poco compacta. En ellas se aprecia una mayor variedad de desgrasantes y coloraciones en las pastas, caracterizada por la abundancia de inclusiones minerales de entre 0,5 y $2 \mathrm{~mm}$, de composición heterogénea y entre las que destaca la presencia de cuarzo, mullita, etc.

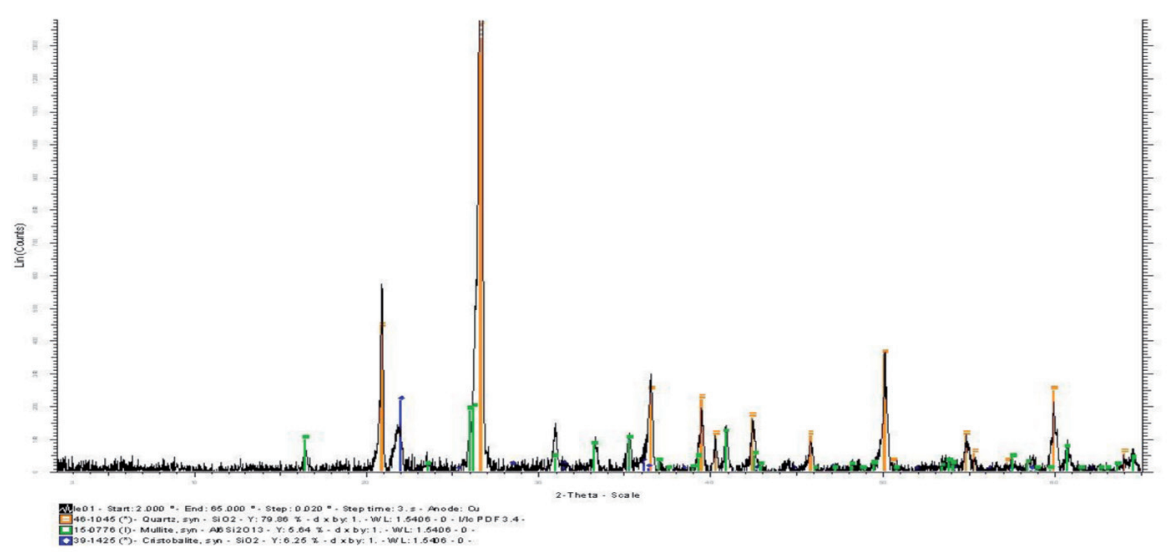

Fig. 3. Análisis mineralógico realizado a un fragmento de cerámica plenomedieval.

${ }^{33}$ J.J. García, D. Peterson, I. García, L. García, Introducción al conocimiento de la viaria romana, pp. 135-163; J. Vidal, Caminos y puentes (en prensa).

${ }^{34}$ C. Estepa, Estructura social; J.J. Sánchez, La configuración de un sistema de poblamiento. 
La técnica de fabricación empleada a la hora de modelar las arcillas es a su vez el torneado a partir del urdido. Se distinguen frecuentes irregularidades en las secciones de los recipientes, así como abundantes huellas digitadas en sus fondos y cuerpos. Los análisis físico-químicos con los que contamos hasta el momento, muestran que la temperatura alcanzada por las cerámicas en los hornos se mueve entre los 1100 y $1300^{\circ} \mathrm{C}$, por encima pues de los alcanzados en la gris leonesa $\left(900-1000^{\circ} \mathrm{C}\right)$. Asimismo, se observa un significativo incremento en el número de formas, entre las que predominan las ollas, seguidas de piezas destinadas a servicio de mesa como jarras y platos, además de recipientes dedicados a la iluminación, grandes contenedores de líquido, etc.

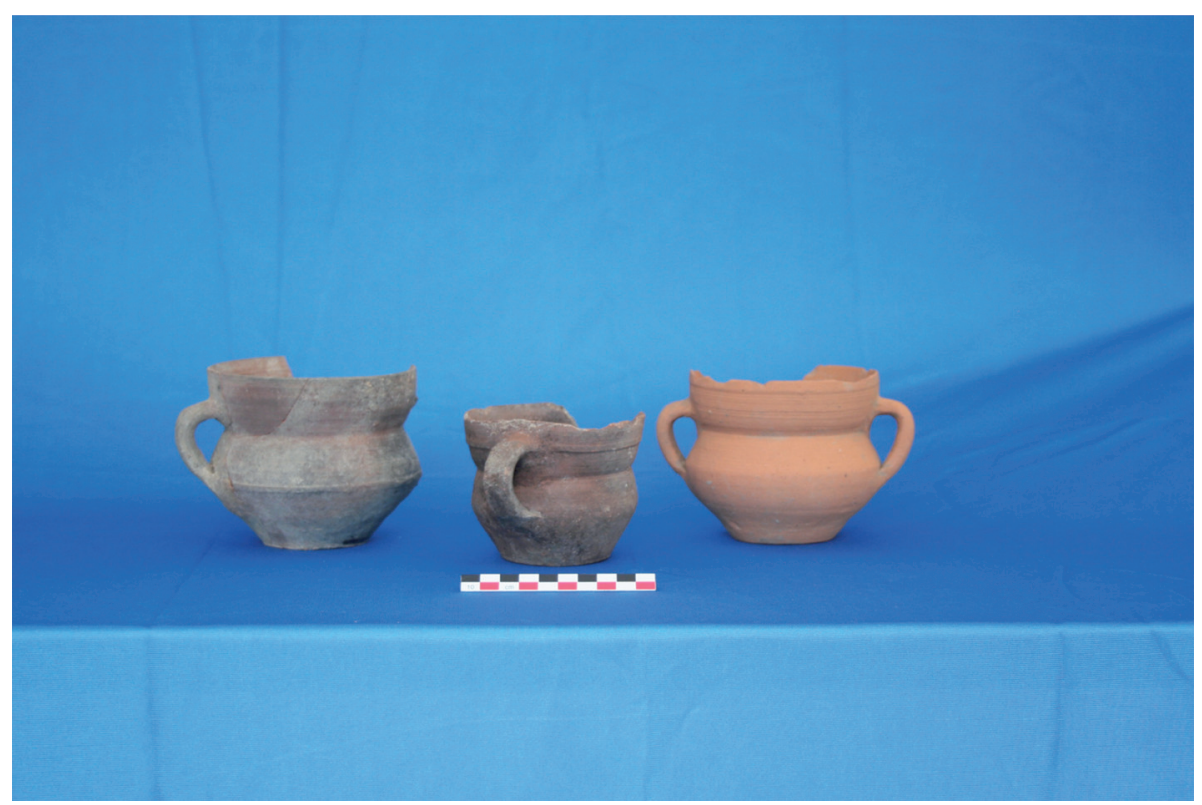

Fig. 4. Cerámicas de la Plena Edad Media.

En cuanto a los motivos decorativos se identifican una mayor variedad de acabados: reticulados, incisiones, punciones, botones aplicados o pintura, entre otros. 
Tabla 2: Tipología de la producción cerámica plenomedieval.

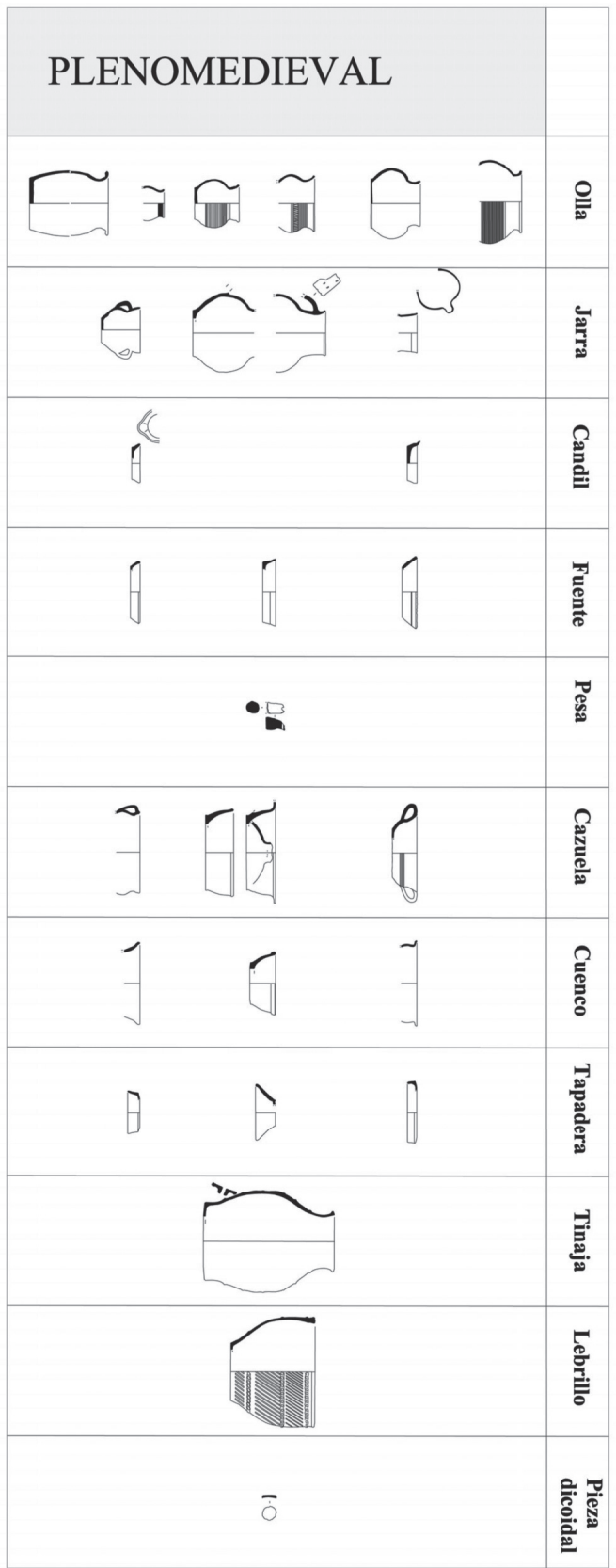


También, en varios contextos plenomedievales hacen acto de presencia producciones foráneas. Las observaciones macroscópicas nos han permitido constatar que las pastas que presentan corresponden a arcillas silíceas muy decantadas, de textura bastante compacta y de colores variados que pueden oscilar entre el ocre y el gris. Se trata pues de producciones netamente diferentes de las autóctonas, presentando escasos desgrasantes minerales, que son bastante uniformes y de pequeño tamaño, entre 0,5 y $1 \mathrm{~mm}$. Algunas de estas piezas son fabricadas a molde y cuentan con acabados vidriados. Tal es el caso de las halladas en el Castro de los Judíos (Figura 5) ${ }^{35}$ o en la calle Santa Marina de la ciudad de León ${ }^{36}$. La presencia de recipientes foráneos denota una cierta dinamización de los intercambios comerciales entre la ciudad y otros territorios peninsulares, dado que se asemejan a las producciones del área meridional de la Península que datan de los siglos XI-XII como las localizadas en el Ribāt da Arrifana (Aljezur, Algarve) $)^{37}$.

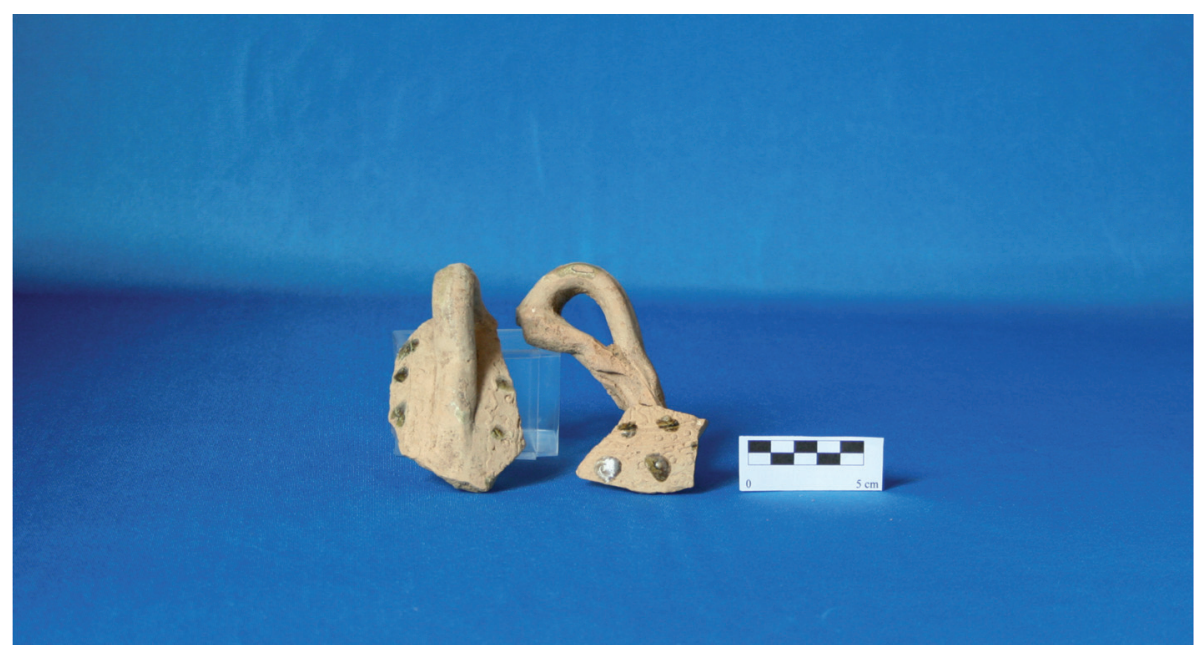

Fig. 5. Fragmento de cerámica vidriada.

En este misma línea, se aprecia también que las producciones cerámicas elaboradas en León tienen un área de distribución mayor que las anteriores, dado que se han encontrado no sólo en la ciudad (los solares no 7, 11 y 13 de la calle San Pelayo o la Plaza Mayor) y su alfoz (el castillo de Alba, el Castro de los Judíos, Ardón o Los Corcales, entre otros $)^{38}$ sino incluso en zonas algo más alejadas, como la comarca de Los Oteros o Valencia de don Juan, situadas a uno cincuenta kilómetros al sur de la ciudad $^{39}$. No obstante, a pesar de estos innegables avances, tal y como hemos podido comprobar, las piezas siguen fabricándose mediante el uso de la torneta y la presión manual.

\footnotetext{
${ }^{35}$ R. Martínez, Análisis de la producción y distribución de la cerámica, pp. 143-187.

${ }^{36}$ J.C. Álvarez, Excavaciónarqueológica C/ Santa Marina, V. García, Excavación arqueológica.

${ }^{37}$ R. Gomes, M. Gomes, Quotidiano, p. 92.

${ }^{38}$ R. Martínez, Análisis de la producción y distribución de la cerámica, pp.143-187/268-275.

${ }^{39}$ J.L. Alonso, Historia; J.A. Gutiérrez, C. Benéitez, Aportacion, pp. 539-548.
} 
Para el conocimiento de la actividad alfarera durante este período contamos con un testimonio arqueológico de singular importancia: el alfar de los "Los Corcales". Se trata de un centro productor de recipientes cerámicos ubicado al norte del alfoz leonés, en un espacio de montaña, paso intermedio entre las actuales provincias de León y Palencia. En los trabajos de campo se identificaron la base de un horno y parte de otro, así como los testares asociados a los mismos. Estos han sido datados mediante cronologías relativas en momentos plenomedievales ${ }^{40}$. Estamos ante los restos, bastante arrasados, de unas estructuras de combustión de planta casi ovalada, erigidas mediante cantos rodados de mediano tamaño trabados con barro. En ellos se distinguen dos cámaras perfectamente diferenciadas. Por un lado, la de combustión que cuenta con una planta paratriangular, situada en la mitad suroriental de la estructura. Sus paredes se levantan mediante la superposición de bloques de cuarcita unidos con arcilla y al interior se encuentra un potente relleno a base de ceniza y carbones. Aquellos presentan rubefacción de la arcilla empleada para la construcción de los muros e incluso del propio estrato geológico. La segunda de las cámaras, la de cocción, se encuentra justo en frente de la anterior. Ambas están separadas por una especie de tuberas, que permiten la entrada de aire caliente hacia las partes altas del horno. Este espacio cuenta con una planta semicircular y con una superficie recubierta con barro rubefactado. Se desconoce tanto el alzado como el sistema de cierre con el que contaba esta estructura ${ }^{41}$.

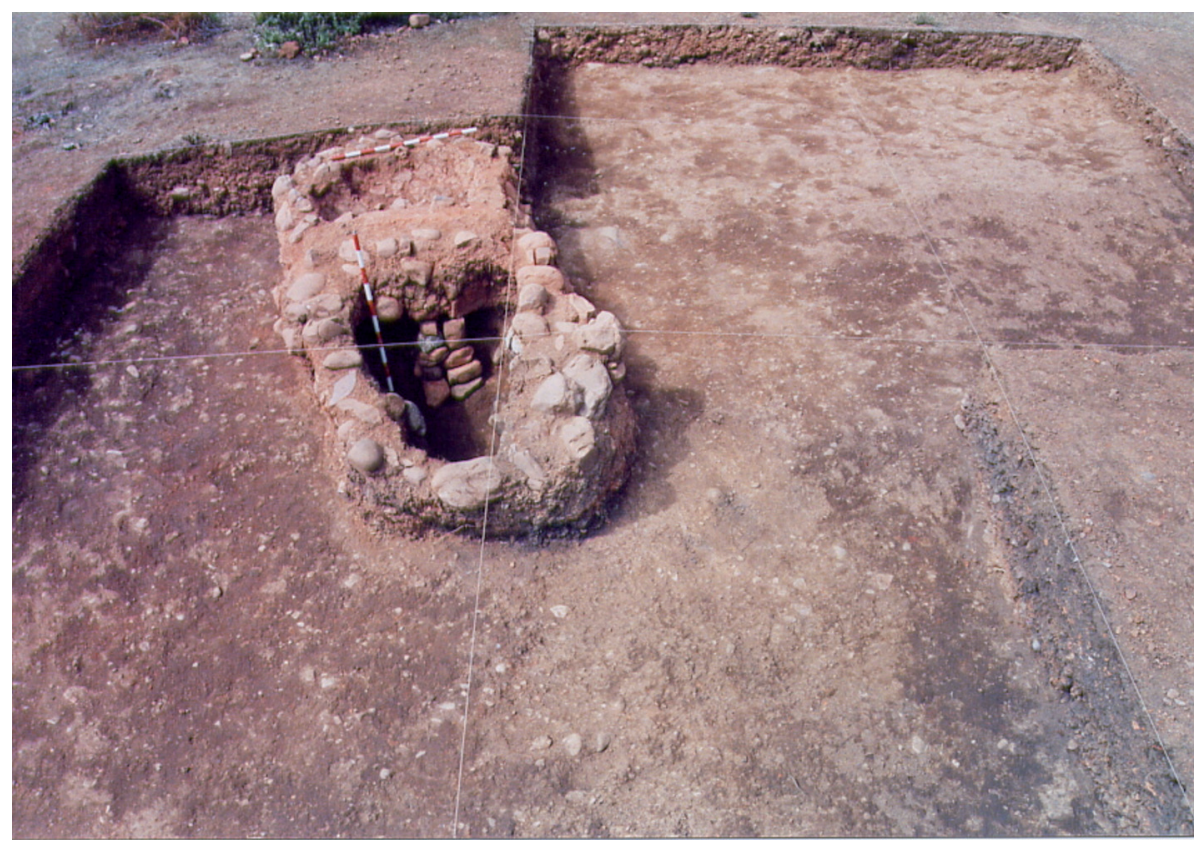

Fig. 6. Estructura de cocción exhumada en "Los Corcales" (autor: Óscar Alonso Gregorio).

${ }^{40}$ R. Martínez, Análisis de la producción y distribución de la cerámica, pp. 276-285.

${ }^{41}$ O. Alonso, Propuesta, pp. 8-40; O. Alonso, Trabajo, pp. 4-35. 
Al margen de la producción ollera en el entorno legionense, desde mediados del siglo XII, y de un modo más claro a partir del XIII, las fuentes documentales verifican ya, aunque sea de un modo muy limitado, la existencia de alfareros dentro de la urbe, en torno al barrio de San Marcelo. No olvidemos que este espacio albergaba las principales actividades mercantiles y artesanales de la ciudad en la época, por lo que no es de extrañar que los alfareros se encuentren allí desempeñando su oficio. Esta zona mantendrá su relación con el sector durante buena parte del Medievo ${ }^{42}$. Su presencia tiene como consecuencia directa la aparición en las fuentes manuscritas de algunos de sus integrantes. La primera referencia localizada hasta la fecha data de 1165. Este año el prior de San Isidoro, Martín Muñoz, concedía a los pobladores del arrabal de Renueva unos terrenos extramuros, en las proximidades del monasterio. Entre los testigos aparecía el alfarero "Pelagius", vecino de San Marcelo ${ }^{43}$. A comienzos del siglo XIII aparece el nombre de otro artesano. En una escritura, fechada en mayo de 1219, se venden las propiedades que el ollero llamado Gutierre poseía en las villas de San Esteban, Vega de Infanzones y Trobajuelo, en el entorno de la ciudad ${ }^{44}$. Por otro lado, en el testamento del canónigo Pedro Fernandi de Morilla del año 1227, se hace una relación de las personas con las que el clérigo había contraído deudas. Una de ellas era el ollero Petrus Dominici, al que el testador manda se le entreguen treinta sueldos ${ }^{45}$.

Además de las esporádicas referencias a algún que otro alfarero, en el último tercio del XIII nos encontramos ya con una alusión a un espacio de labor. El 19 de abril de 1278, cuando Mayor Martínez cede al cabildo de León unas casas que poseía en las proximidades de San Marcelo y especifica los límites de esas propiedades, menciona la existencia de una "caleya hu mueran los olleros" 46 . Es decir, se está hablando de un testar; un espacio dedicado a depositar los materiales de desecho de la producción cerámica que, por lo general, suele estar asociado a un taller más o menos cercano. En este caso las referencias documentales parecen verse avaladas por los trabajos de campo que se desarrollaron a comienzos de los noventa en el Edificio Pallarés situado en el entorno del llamado "Postigo de Ollerías". Esta puerta se emplaza en pleno barrio artesanal de San Marcelo, donde se produce la unión, por su lado noroeste, de la cerca bajomedieval y la muralla tardoantigua. Al mismo tiempo, se halla próxima a la Puerta Cores, una de las principales entradas a la ciudad desde época romana (Figura 7). Se trata de una alusión toponímica, sin duda, enormemente gráfica. Los arqueólogos responsables de aquellos trabajos hallaron un potente nivel con cerámica medieval en el que abundaban fragmentos con los defectos de cocción típicos de aquellas hornadas con malformaciones que son eliminadas por los artesanos ${ }^{47}$.

${ }^{42}$ A. Represa, Evolución, pp. 243-282.

${ }^{43}$ CSIL, núm. 81; M.E. Martín, Patrimonio.

${ }^{44}$ CCL, núm. 1.881; J.M. Fernández, Colección, VI.

${ }^{45}$ CCL, núm. 1.946; J.M. Fernández, Colección, VI.

${ }^{46}$ CCL, núm. 2.380; J.M. Fernández, Colección, IX.

${ }^{47}$ F. Miguel, V. García, Intervención arqueológica, pp. 175-206. 


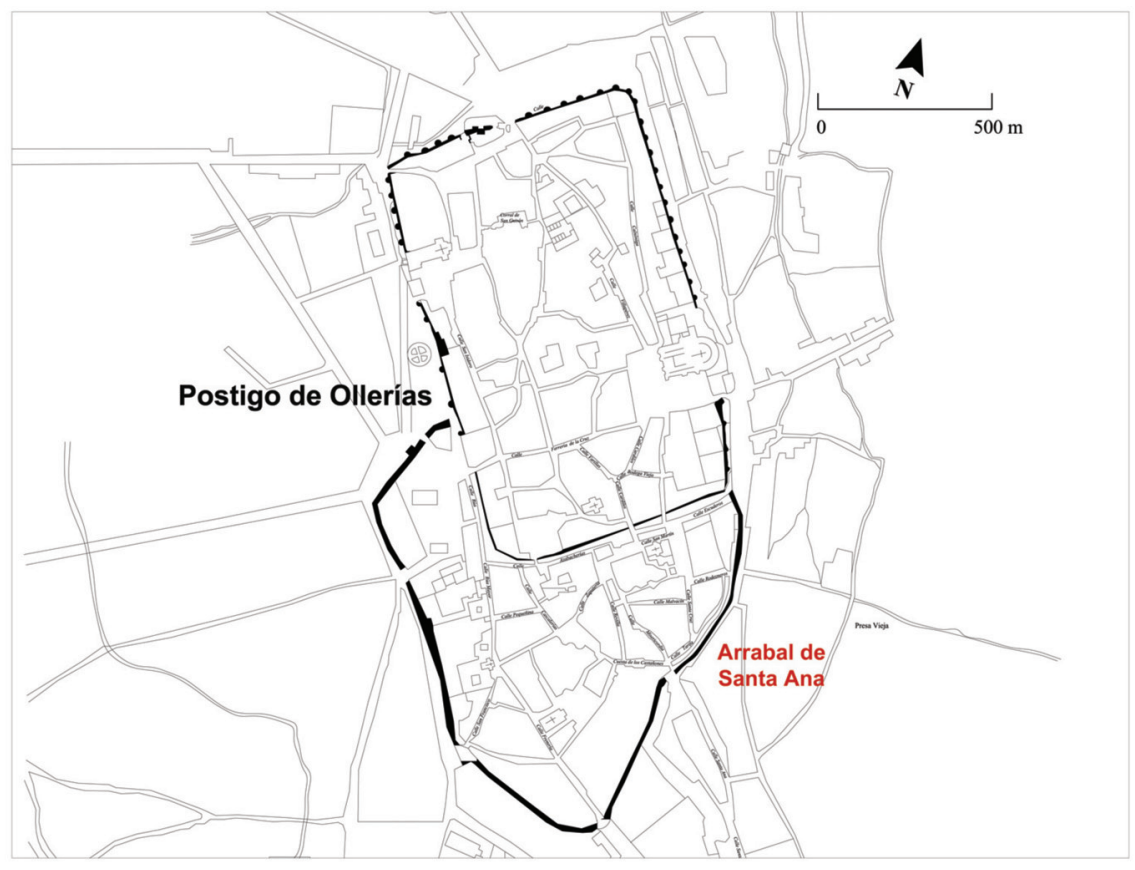

Fig. 7. Emplazamiento del Postigo de Ollerías.

Avanzando ya en el tiempo, junto a la constatación de la existencia de algunos olleros y de un testar, la documentación comienza a ofrecernos a su vez información sobre la presencia en el entorno de la ciudad de enclaves de recogida de materias primas. Todavía en el siglo XIII, en una donación efectuada por la familia de Isidro Juan a la iglesia de Santa María de Regla, se hace alusión a la existencia de unas barreras situadas en esta parroquia, a extramuros ${ }^{48}$. Años más tarde, en 1360, en una carta de foro censual, los foreros reciben de San Isidoro una barrera, próxima a la ermita de San Esteban, ubicada también fuera de murallas. En este caso parece que la extracción de la arcilla se encaminaba a la producción tejera, dado que en las condiciones del contrato se establecía el suministro al monasterio de quinientas tejas de barro a cambio de la explotación ${ }^{49}$. No sería de extrañar, de todos modos, que el yacimiento de arcilla pudiera ser también utilizado por los olleros, habida cuenta de su proximidad a la urbe.

Por otro lado, en el alfoz legionense, o en tierras próximas a él, continúan apareciendo referencias toponímicas que dan pie a pensar en la posible existencia de focos alfareros. Algunas de estas localidades ya quedaban reflejadas para el período altomedieval, caso de la villa de Ollarios o de Nava de Olleros. Pero también surgen otras nuevas como Villar de las Ollas ${ }^{50}$. Incluso, aunque en ámbitos bastante más alejados de la capital, se encuentran alusiones a la explotación de posibles barreros. Es

${ }^{48}$ CCL, núm. 2.657; J.M. Fernández, Colección, IX.

${ }^{49}$ CSIL, núm. 179; M.E. Martín, Patrimonio.

${ }^{50}$ CCL, núm. 2.598; J.M. Fernández, Colección, IX. 
el caso de una escritura de venta de 1283 referida al lugar de Campo de Luna, en la Montaña Occidental leonesa, a unos sesenta y cinco kilómetros de la ciudad, en la que se habla de los "solos de los olleros" 51.

Durante los siglos XIV y XV, la ciudad fue extendiendo su entramado hacia su área meridional que, tal como señalamos, quedará delimitada a través de la construcción de la Nueva Cerca. Esta expansión provoca un notable incremento de las actividades comerciales y artesanales hacia la nueva área amurallada, sobre todo, en el entorno de las parroquias de San Martín y el Santo Sepulcro. La aparición de este nuevo foco significó el paulatino desplazamiento del eje de influencia económica de la ciudad desde el entorno de San Marcelo hacia él. En consecuencia, el sector alfarero leonés irá, poco a poco, abandonando su ubicación en la zona oeste de la urbe para ocupar el nuevo espacio. Se establecerán, fundamentalmente, en la parroquia del Santo Sepulcro. La toponimia bajomedieval da muestras del desarrollo de este proceso, al atestiguar la presencia en aquel ámbito de una "calle cantareros" 52.

La ubicación en este nuevo emplazamiento viene dada por una serie de factores favorables. En primer lugar se trataba, por entonces, de una zona un tanto alejada del espacio de mayor densidad de población, lo que facilitaba el ejercicio de la labor, dadas las incomodidades que conllevaba la cocción de los hornos para el vecindario circundante y el peligro de posibles incendios. Pero a pesar de dicha circunstancia, este ámbito se hallaba muy próximo a la zona comercial de la urbe, con lo que se garantizaba la correcta comercialización de sus productos. Por otro lado, los talleres contaban con zonas de avituallamiento de arcilla cercanas, caso de las barreras de Santa María, entre otras. Finalmente, el suministro de agua, materia imprescindible para el desarrollo del oficio, estaba también garantizado a través de la cercana Presa Vieja.

Por su parte, los lotes cerámicos bajomedievales reflejan un nuevo avance desde el punto de vista técnico, directamente relacionado con la introducción del torno rápido que proporciona perfiles uniformes y superficies muy homogéneas. La aplicación de este instrumento es la principal diferencia con respecto a los siglos antecedentes, puesto que los análisis de pastas muestran que se sigue empleando una matriz arcillosa bastante decantada, que alberga los mismos desgrasantes de reducido tamaño -cuarzo y mullita- que los utilizados en la elaboración de la vajilla plenomedieval.

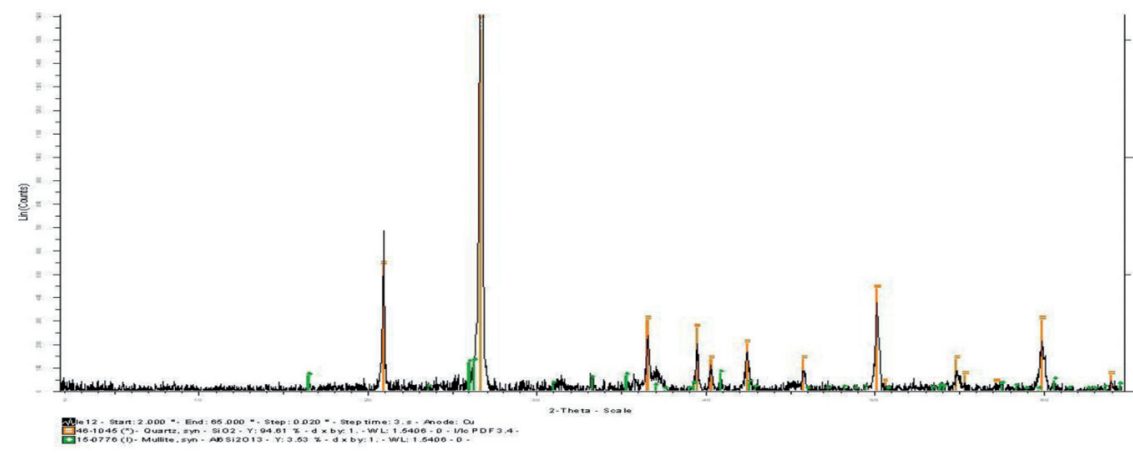

Fig. 8. Análisis mineralógico realizado a un fragmento de cerámica bajomedieval.

${ }^{51}$ CCL, núm. 2.428; J.M. Fernández, Colección, IX.

${ }^{52}$ C. Álvarez, La ciudad de León, pp. 65-73. 
Además, los recipientes siguen sometiéndose a una gradación idéntica $\left(1100-1300^{\circ} \mathrm{C}\right)$ y los tipos formales prácticamente se repiten -jarras, tazas, platos, ollas o cuencos-, si bien se observan ciertos cambios en su morfología, como es el caso de las jarritas carenadas (Tabla 3).

Tabla 3. Tipología de la producción cerámica de la Baja Edad Media.

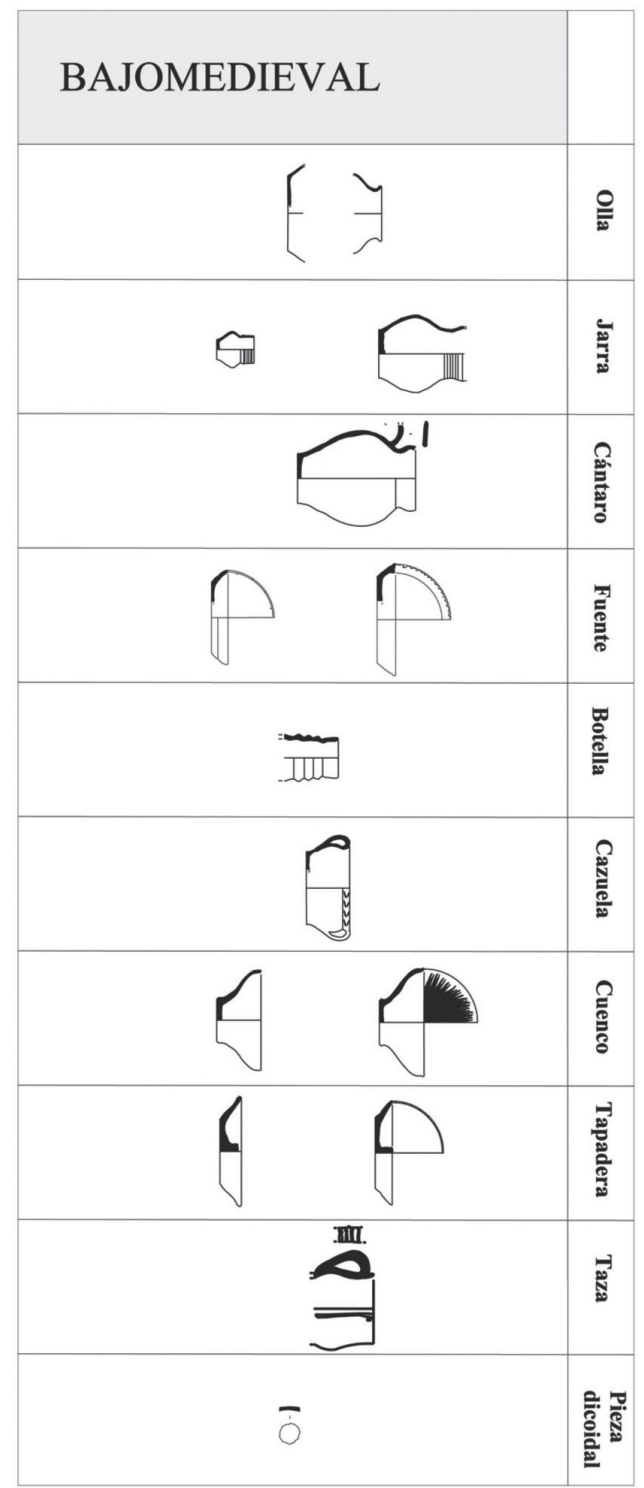


Dicha forma es propia de la Baja Edad Media y tiene una amplia dispersión tanto en tierras leonesas, como en otros lugares más alejados (Astorga, Benavente o Valladolid $)^{53}$.

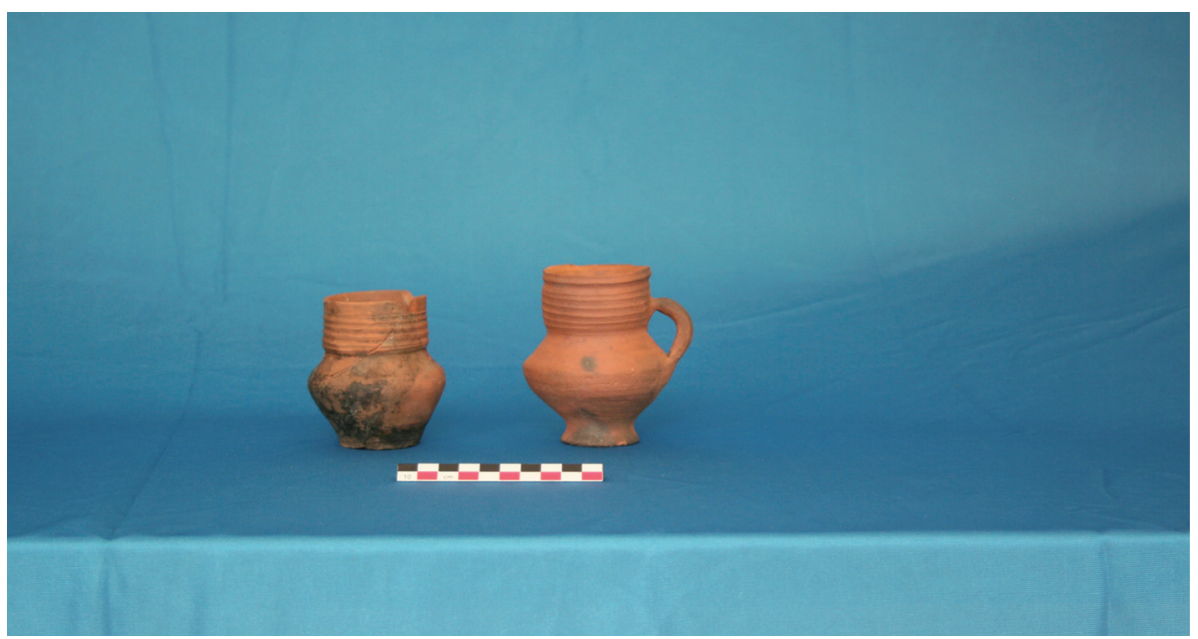

Fig. 9. Jarritas carenadas de cronología Baja Edad Media.

En cuanto a la decoración conviene resaltar el hecho de que se han identificado algunos acabados que tradicionalmente se daban por desaparecidos para estas fechas tan tardías, caso de las líneas de pintura blanca -solar $\mathrm{n}^{\circ} 7$ de San Pelayo- o la aparición ya de recipientes con decoración vidriada -calle Tarifa- ${ }^{54}$.

$\mathrm{Al}$ respecto, hemos de tener en cuenta que el uso de torno complementado con el trabajo manual ha seguido empleándose en las distintas producciones tradicionales del territorio peninsular hasta hace sólo unas décadas. Sirvan como ejemplos conocidos el caso de los centros alfareros zamoranos de Moveros y Pereruela ${ }^{55}$, del asturiano de Faro $^{56}$ o de las localidades portuguesas de Barcelos, Bisalhães o Molelos ${ }^{57}$, entre otras. Asimismo, en las producciones de la localidad leonesa de Jimenez de Jamuz ${ }^{58}$, se evidencia, desde al menos el siglo XVIII, el empleo del torno rápido, así como la cocción de los recipientes en hornos de tiro vertical, práctica que se repite en las alfarerías gallegas de Malpica y Buño ${ }^{59}$ o en las vallisoletanas de Peñafiel y Portillo ${ }^{60}$.

53 J.A. Gutiérrez, H. Larrén, C. Benéitez, A. Turina, Una producción mudéjar, pp. 316-324.

54 J.A. Gutiérrez, H. Larrén, C. Benéitez, A. Turina, Una producción mudéjar, pp. 316-324; R. Martínez, Análisis de la producción y distribución de la cerámica, pp. 268-275.

${ }^{55}$ L. Cortés, La alfarería, pp. 141-163; L. Cortés, La alfarería femenina, pp. 95-107; W. Koper, Guía, 198; E. Sempere, Rutas; R.M. Carnero, Historia.

${ }^{56}$ J.J. Argüello, Un ejemplo de continuidad, pp. 93-100; E. Ibáñez, Cerámica. Rutas.

${ }^{57}$ M. Picon, J. Thiriot, H. Abraços, J.M. Diogo, Estudo em laboratorio, pp. 189-207; E. Sempere,

58 W. Koper, Guía; M. Brando, J.L. González, Alfarería; R. Martínez, El centro alfarero, pp. 309-332.

${ }_{59}$ W. Koper, Guía; E. Sempere, Rutas; L. García, Notas para o estudio, pp. 87-92.

${ }^{60}$ P. González, La cerámica. 
Amén de las referencias toponímicas, en la documentación bajomedieval quedan algunas huellas de la presencia de alfareros en el entorno del barrio del Santo Sepulcro. A comienzos de la década de los sesenta del siglo XV, en un pleito aparece mencionado el ollero de aquella colación Luis Alfonso, al negarse a pagar una serie de cargas concejiles por ser excusado de la iglesia ${ }^{61}$. En 1473, es otro artesano del oficio el que queda plasmado en las fuentes: un tal Rodrigo Alfonso, morador al mercado a la collaçión de Santo Sepulcro y quizás pariente del anterior. En el documento el poder concejil le concede en foro perpetuo una tierra de su propiedad, sita junto a la Presa Vieja. La cesión tiene por objeto que el ollero pueda erigir en él casa, o huerto, o corral, o forno para coçer ollas. En compensación, Rodrigo Alfonso ha de pagar en foro al mayordomo del concejo, diez maravedíes anuales por la fiesta de San Martín ${ }^{62}$.

Asimismo durante la Baja Edad Media la documentación nos muestra la existencia de olleros residiendo en localidades relativamente próximas a la capital, caso, por ejemplo, de Sorribos, Santo Martino de Fonfebro o Santa María de Alba ${ }^{63}$. No sería de extrañar que, atendiendo a esa cercanía, existieran en ellos centros que encaminasen parte de su producción al mercado urbano, además de al rural circundante.

Las breves referencias documentales y toponímicas que existen para el caso específico de la ciudad tienen su prolongación y aval en las excavaciones arqueológicas. Precisamente en este nuevo espacio de actuación de los alfareros leoneses ha sido hallado recientemente un alfar de cronología bajomedieval. En efecto, en un área limítrofe entre las parroquias medievales de San Martín y el Santo Sepulcro, se han exhumado varias estructuras de combustión que parece que estuvieron funcionando al mismo tiempo. La numismática y los restos cerámicos hallados apuntan a una prolongación en el uso de estas instalaciones durante los inicios de la Época Moderna, siendo posible que su fin estuviese relacionado con un incendio ${ }^{64}$.

Así, desde el punto de vista arqueológico, contamos con un ejemplo sumamente interesante para estudiar las características de la producción cerámica medieval en la ciudad de León. En efecto, en las excavaciones desarrolladas en el entorno del barrio de Santa Cruz, se sacaron a la luz los restos de un alfar que data de los momentos finales de la Edad Media o comienzos de la Edad Moderna. Su ubicación concuerda perfectamente con las referencias documentales que, como ya hemos podido comprobar, señalan al área meridional de la urbe como el espacio ocupado por las labores vinculadas a la producción de cerámica durante la Baja Edad Media ${ }^{65}$. En dicha intervención se localizó un muro de cantos rodados y ladrillos trabados con mortero de cal, que divide en dos el espacio de labor. En la esquina suroeste del sondeo, se exhumó una estructura de planta circular que se encuentra semiexcavada en el suelo. Se trata de un horno-brasero conformado por una sola hilada de cantos rodados trabados con tierra que, desde el punto de vista funcional, se identifica con una pequeña estructura de cocción utilizada en la preparación de los óxidos del alfar. Dicha estructura presenta enormes similitudes con los hornos-brasero exhumados en las excavaciones del barrio alfarero de Marsella y que datan del siglo XIII ${ }^{66}$. En el perfil sur, se sacó a la luz un muro de mampostería que subdivide en dos esta zona. Por un lado, la más septentrional corresponde al testar y, por otro, la más meridional

${ }^{61}$ CCL, núm. 3.738; C. Álvarez, Colección Documental, XII.

${ }^{62}$ CCL, núm. 3.738 y 3.912; C. Álvarez, Colección Documental, XII.

${ }^{63}$ CCL, núm. 2.598; J. M. Fernández, Colección Documental, IX.

${ }^{64}$ R. Martínez, Análisis de la producción y distribución de la cerámica, pp. 105-111.

${ }^{65}$ R. Martínez, El alfar (en prensa).

${ }^{66}$ H. Marchesi, J. Thiriot, L. Vallauri, El barrio de alfareros, pp. 35-43; H. Marchesi, J. Thiriot, L. Vallauri, Le Faubourg des olliers, pp. 338-345; H. Marchesi, J. Thiriot, L. Vallauri, Marseille. 
parece concentrar las estructuras de producción propiamente dichas, ya que se identifica en ella el mencionado horno-brasero, la boca de alimentación del horno y dos pavimentos de tierra pisada.

También, en la esquina suroeste del sondeo se descubrió otro horno-brasero de planta circular, mientras que en el ángulo noroeste, apareció a su vez una nueva estructura de combustión, en este caso de planta circular, que cuenta con dos cámaras, la de cocción y el hogar, separadas mediante un pequeño tabique de cantos rodados y bloques de cuarcita trabados con tierra.

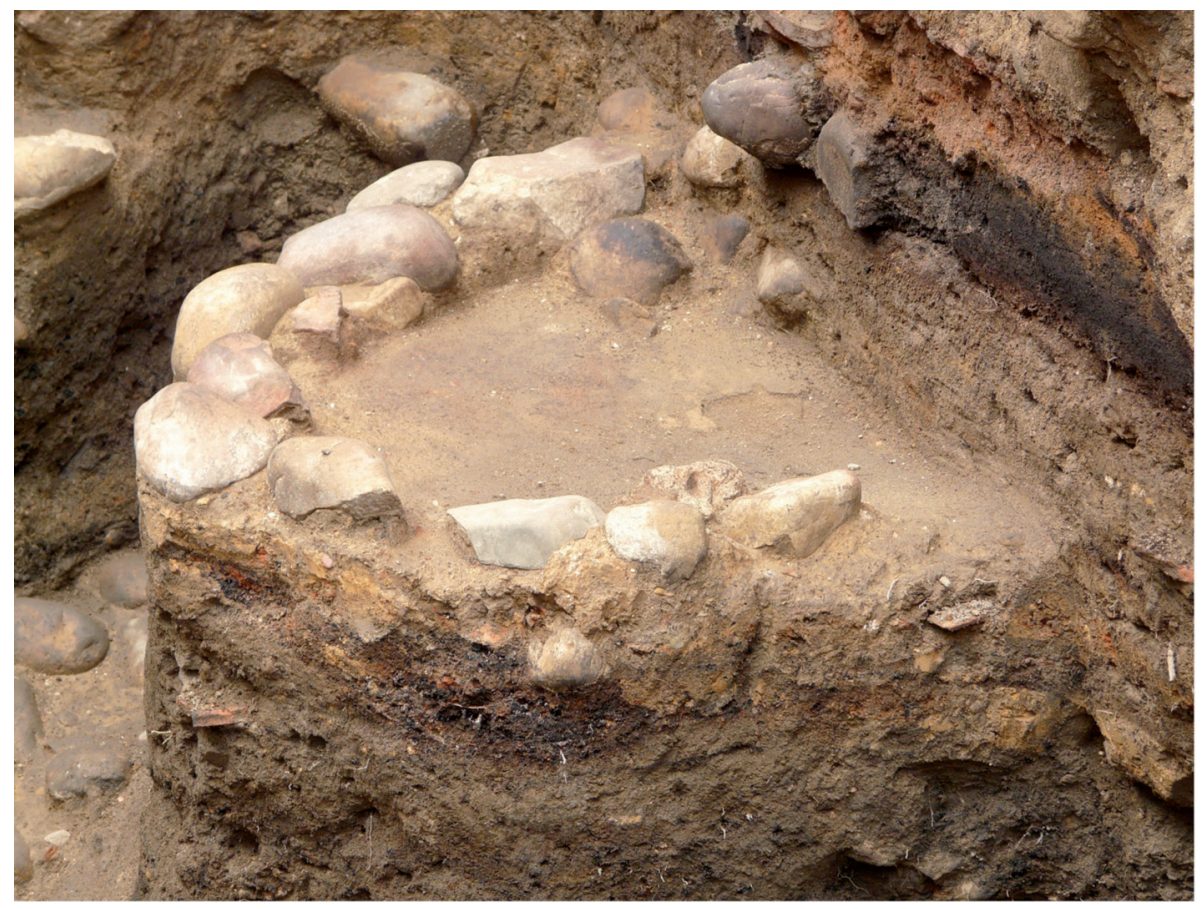

Fig. 10. Horno-brasero del alfar de Santa Cruz (autora: Ma Isabel Cano Gómez).

Sobre este muro se encontraron fragmentos de ladrillo y adobe rubefactado que parecen corresponder a las paredes del horno. Además, junto a esta estructura, se localizaron otros dos hornos-braseros con las mismas características edilicias que el anterior. Dado el nivel de arrasamiento que presentan, desconocemos los sistemas de cierre, tanto de los hornos como de los hornos-braseros.

En cuanto a los restos arqueológicos, se recogieron un importante número de piezas entre las que destacan las jarritas carenadas o los cuencos de cronología bajomedieval. 


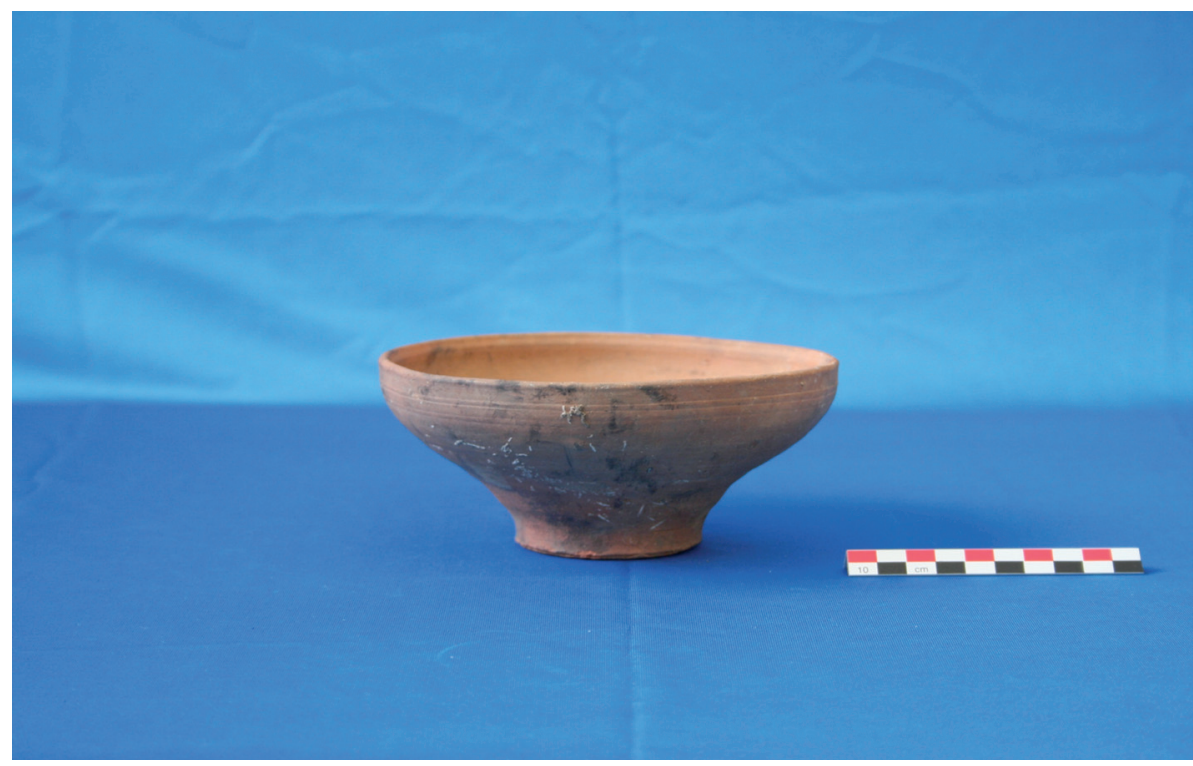

Fig. 11. Cuenco de época bajomedieval.

Asimismo, tiene adscritos un grupo de materiales arqueológicos cuya utilidad parece estar estrechamente relacionada con la producción alfarera, tales como fragmentos de parrilla, azadas de hierro de reducido tamaño, bolas de arcilla de forma esférica sin cocer o varios hilos de bronce.

En alfar pudo quedar inutilizado en el incendio que arrasó parte del área meridional de la ciudad a mediados del siglo XVII ${ }^{67}$, o bien fue devastado a raíz de un accidente de menor impacto producido por su propia actividad, lo que sin duda era muy común en la época ${ }^{68}$.

Precisamente el evidente riesgo que suponían los hornos, ya fueran para la fabricación de cerámica, para pan o de otro tipo, y los consecuentes conflictos que podían surgir entre sus propietarios y los vecinos del entorno, es algo conocido para el panorama urbano del momento. En León, como en otras ciudades, el gobierno municipal, al menos desde el bajomedievo, trató de alejar hacia los arrabales este tipo de actividades, a fin de reducir el peligro de posibles incendios. De todos modos, el alfar descubierto, si bien se encontraba dentro del nuevo ámbito de actuación del artesanado dedicado al barro, se situaba todavía intramuros, quizás porque en el momento de su construcción todavía no se dejaba sentir en aquella parte de la ciudad una excesiva presión demográfica. Sin embargo, a medida que León vaya creciendo, los talleres y sus hornos se irán ubicando en espacios próximos pero ya fuera de murallas, en el llamado arrabal de Santa Ana (Figura 6).

${ }^{67}$ L.M. Rubio, Historia de León, vol. 3; E. Campomanes, F. Muñoz, Memoria de la excavación.

${ }^{68}$ Incendios idénticos se documenta a finales de la Edad Media, comienzos de la Edad Moderna en localidades como Medina del Campo (AGS, Consejo Real de Castilla, Caja 102, n 20), Madrid (ARCHV, Pleitos Civiles, Caja 137, n² 2) o la ciudad de Cáceres (ARCHV, Pleitos Civiles, Caja $\left.1.981, \mathrm{n}^{\circ} 2\right)$. 
En este contexto es en el que debemos integrar el pleito hallado en el Archivo de la Real Chancillería de Valladolid, sostenido entre Miguel Gutiérrez, zapatero de dicho arrabal, y el ollero Pablo Rodríguez de Acuña ${ }^{69}$. El documento, si bien se aleja un tanto del espacio cronológico por nosotros acotado en nuestro estudio, resulta de gran utilidad, al ofrecernos una visión relativamente próxima a la realidad del sector alfarero leonés en el período bajomedieval. De hecho, el proceso se desarrolla entre 1532 y 1535 , haciendo algunos de los testigos que en él aparecen alusiones a tiempos anteriores. La razón del litigio es la firme oposición que hace el zapatero a la pretensión de su vecino de "edificar horno de cozer ollas e cantaros" en el corral que linda con la casa en la que él mora. Gutiérrez considera aquella obra enormemente perjudicial y acude a la justicia de la ciudad que, en 23 de marzo de 1533, condena al ollero a paralizar las obras y a derribar lo hasta el momento construido en un plazo de seis días, so pena de una multa de 2.000 maravedíes. Ante aquella sentencia, Pablo Rodríguez recurrirá al tribunal real vallisoletano.

Tanto en el alegato del ollero como en los testimonios que adjunta encontramos una valiosísima información. A la hora de defender la erección del horno, Rodríguez afirma no existir perjuicio para las casas de alrededor, dado que se está edificando apoyado sobre una alta tapia y no sobre una vivienda. Además, como prueba de lo justo de su reclamación, y esto es lo más interesante para nosotros, asegura "que en toda la dicha colación e barrio de Santana biben los mas ofiçiales de cantareros e olleros e todos los hornos están entre las casas de los vezinos como el mio". Se trata pues de la corroboración documental de la concentración en esta zona del sector, como nos hacían sospechar las referencias documentales, toponímicas y arqueológicas. Esta afirmación se encuentra ratificada por cuatro testigos. Uno de ellos, llamado Diego Alonso, de cuarenta años de edad y vecino del mismo arrabal, nos habla de la existencia con anterioridad en aquel mismo solar de otro taller y horno que pertenecía a un tal Gutierre de Onzonilla. Esta declaración será ratificada por otros cuatro testigos:

\begin{abstract}
dixo este testigo que bibiendo e morando en las cassas en que agora bibe e mora Pablos ollero Gutierre de Honçonilla, el qual tuvo alli horno de cantarero adonde agora lo hacía y hedificava el dicho Pablo se cozer qual sus ollas e cantaros e ansy lo vio por tiempo y espaçio de veinte e çinco años e que durante el dicho tiempo no vi oque el dicho horno hiciese dapnio ni perjuizio a ninguno ni menos vyo que nadie se quexiasse porque allo lo tenia ${ }^{70}$.
\end{abstract}

También los testimonios aportados por el zapatero constatan la existencia de un horno anterior, si bien señalan que cuando el citado Onzonilla trabajaba en la zona, aquella se hallaba rodeada de tapias, no existiendo una casa próxima. Este aspecto parece apuntar, de nuevo, a las facilidades que ofrecía aquel espacio, en un primer momento, para centralizar las actividades alfareras, al reducirse considerablemente el peligro de incendios y afectar a un número muy restringido de vecinos. Esa situación varió a medida que la ciudad fue expandiéndose, lo que provocó la aparición de tensiones.

Precisamente el principal argumento de Miguel Gutiérrez es recalcar el peligro que conllevaría a su casa y a toda la vecindad la construcción de aquella estructura. De hecho, varios testigos afirmaban que el de Onzonilla había provocado en aquellos tiempos un incendio que había llegado al corredor de la casa y que logró ser

${ }^{69}$ ARCHV, Pleitos Civiles, Caja 1.721, ${ }^{\circ} 4$.

${ }^{70}$ ARCHV, Pleitos Civiles, Caja 1.721, $\mathrm{n}^{\circ} 4$. 
sofocado merced al auxilio de los vecinos. La certeza de ese peligro queda reflejada de una manera muy ilustrativa en la respuesta de uno de ellos:

que save que quando rojan el horno para el cozer la dicha obra que la llama sale muy alta e sienpre se acostumbra a hazer los dichos hornos apartados de vezindad porque no agan dapnio porque sy anda ayre las mirçinas pueden ençender las cassas e que sy el dicho Pablos haze alli el dicho horno es gran perjuysio para el dicho Miguel Gutierrez e para la vecindad ${ }^{71}$.

El proceso concluirá el 12 de octubre de 1535 cuando los jueces de la Chancillería fallen a favor del ollero, revocando la sentencia del teniente corregidor de León:

Por ende que devemos revocar y revocamos su juicio y sentencia del dicho teniente de corregidor y haciendo en este pleito lo que de justicia debe ser fecho que devemos mandar y mandamos que el dicho Pablos de Acuña puede hazer y haga el horno sobre que en este dicho pleito en el lugar donde antes solia estar y ansy lo pronunciamos y mandamos y no hazemos condenación de costas.

Este pleito, como hemos podido comprobar, ha arrojado una serie de informaciones sumamente interesantes, en tanto en cuanto nos han servido para ratificarnos en nuestras afirmaciones sobre la evolución del sector alfarero en la ciudad durante los siglos bajomedievales. La presencia constatada de olleros trabajando en la colación del Santo Sepulcro desde, al menos, mediados del siglo XV, contradicen las afirmaciones sostenidas por algunos autores en trabajos relativamente recientes. En efecto, Miguel Hernández y García Marcos, consideraban que el traslado del sector alfarero desde el entorno de San Marcelo a este nuevo emplazamiento era un fenómeno mucho más reciente que podía estar relacionado con la construcción, en la segunda mitad del siglo XVI, del palacio de los Guzmanes ${ }^{72}$.

Lo que sí es cierto es que la relación entre el sector alfarero y el arrabal meridional de la urbe se consolidará a lo largo de la Edad Moderna. En el padrón de moneda forera de 1625 aparecen tres vecinos cantareros: Pedro Fernández, Bartolomé Fernández y Francisco Díez. Es posible que pudiera existir alguno más, dado que en dicho recuento hay un número significativo de vecinos de los que no se especifica su oficio $^{73}$. Unos años más tarde, en el padrón de 1638, aparecen cuatro desarrollando esta actividad: Gregorio Pérez, un tal Alonso, Antonio Díez y Juan de Monzón. Además se hace referencia a Catalina, la viuda del cantarero Pedro Fernández que aparecía en el de $1625^{74}$. Todavía a mediados del siglo XVIII, el Catastro del Marqués de la Ensenada sigue mostrándonos la concentración del sector en aquel entorno ${ }^{75}$.

Los datos de la época Moderna nos sirven, finalmente, para constatar dos circunstancias que, creemos, son perfectamente extrapolables para el mundo bajomedieval. Por un lado, nos encontramos ante un sector relativamente reducido en cuanto a efectivos; todavía en 1752, cuando la ciudad contaba con unos niveles demográficos notablemente superiores a los del siglo XV, el número de vecinos cantareros era so-

\footnotetext{
${ }^{71}$ ARCHV, Pleitos Civiles, Caja 1.721, nº 4.

${ }^{72}$ F. Miguel, V. García, Intervención arqueológica, pp. 175-206.

${ }^{73}$ AHML, Caja 659.

74 AHML, Caja 660.

${ }^{75}$ AHPL, Catastro de Ensenada.
} 
lamente de dos maestros y tres oficiales. Por otro, parece que la posición económica de sus integrantes no era precisamente boyante. En el pleito referido del siglo XVI, el ollero Pablo Rodríguez esgrimía como argumento a la hora de solicitar la continuación de las obras de fabricación de su horno, su delicada situación económica. Incluso los testigos de la parte contraria no tienen inconveniente en calificarlo como pobre, término que, desde luego, no se refiere a una pobreza de solemnidad pero sí a una posición un tanto endeble. Esa misma situación parece repetirse en los recuentos de los siglos XVII y XVIII. En consecuencia, es muy posible que durante la Baja Edad Media el sector alfarero mostrase unas características similares: un número reducido y una situación económica nada envidiable.

\section{CONCLUSIONES}

En el presente estudio hemos intentado encuadrar la producción cerámica analizada desde una perspectiva formal, en el contexto demográfico, socio-económico, cultural y político en el que fue generada. Atendiendo a este enfoque hemos procurado cruzar los datos arqueológicos con las referencias documentales con las que contamos hasta el momento.

Los materiales de fines de la Alta Edad Media muestran una producción cerámica muy estandarizada y limitada desde el punto de vista territorial, que tanto formal como ornamentalmente, presente ciertas conexiones con las producciones hispano-visigodas. De hecho, la arqueometría evidencia que estos recipientes han sometido a temperaturas de cocción que no superan los $900-1000^{\circ} \mathrm{C}$. Se trata pues de piezas marcadamente locales y con un reducido ámbito de distribución.

Estas impresiones encajan perfectamente con las fuentes manuscritas de la época que, además, sitúan la existencia de uno o varios centros de fabricación en el suburbio legionense. Hacia esa realidad apunta también la toponimia fosilizada. La escasa circulación los recipientes y su "tosquedad" coinciden con los momentos en los que León comienza a articularse como capital del reino. Por entonces, la urbe presenta un dinamismo económico ciertamente limitado, que tiene su correspondencia en las particulares características de la producción cerámica.

El marcado incremento cuantitativo de vestigios cerámicos en la plenitud medieval, nos hablan del crecimiento de la demanda de este tipo de productos que parece estar vinculada al despegue demográfico y económico de la ciudad en estos momentos. Asimismo, la diversificación de tipos cerámicos nos remite a una diversificación de actividades económicas en una urbe que consolida ahora su papel como centro político, religioso y económico.

Del mismo modo que León se está convirtiendo en un verdadero centro urbano, con la concentración de actividades propias de este mundo, las referencias documentales nos confirman también la presencia de alfareros que desarrollan su actividad murallas adentro. Estas pistas, ciertamente esporádicas, se ven confirmadas por el análisis operado sobre el material cerámico, en donde se evidencia la posible existencia de varios centros productores funcionando al mismo tiempo. El referido crecimiento del sector alfarero tiene como consecuencia inmediata la expansión del área de distribución de sus productos.

Los recipientes de cronología plenomedieval, evidencian una notable evolución desde el punto de vista técnico en comparación con la anterior. Los análisis químicos muestran que para este momento, la temperatura alcanzada por las cerámicas en los hornos se mueve ya entre los 1100 y $1300^{\circ} \mathrm{C}$. Asimismo, se aprecia un significativo incremento en el número de formas y motivos decorativos. Se documentan asimismo algunas producciones foráneas, lo que evidencia relaciones comerciales 
entre la ciudad y otras zonas peninsulares. En esta misma línea, se aprecia igualmente que las producciones cerámicas elaboradas tienen un área de distribución mayor que las altomedievales. No obstante, a pesar de estos innegables avances, las piezas siguen fabricándose mediante el uso de la torneta y la presión manual.

Durante la Baja Edad Media, se produce una concentración de la actividad comercial y artesanal de la urbe hacia el flanco meridional, delimitado por la Nueva Cerca construida en aquellos momentos. Siguiendo esta dinámica, la documentación constata el traslado del sector alfarero desde el barrio de San Marcelo a este espacio. El hallazgo del alfar del barrio de Santa Cruz, confirma unas impresiones que, a su vez, se ven reforzadas por la documentación de época Moderna. En ella se evidencia la continuidad del sector alfarero en el territorio al que se había desplazado en la Baja Edad Media y la discreta situación económica de este sector en el contexto general urbano del momento.

En todo este espacio de expansión urbana, aparecen restos cerámicos de semejantes características a los encontrados en aquel alfar. Es necesario, también, resaltar las evidentes continuidades que se aprecian en las producciones bajomedievales y modernas. Es decir, no se vislumbra entre ambos momentos transformaciones tecnológicas.

Los lotes cerámicos bajomedievales reflejan un nuevo avance desde el punto de vista técnico, directamente relacionado con la introducción del torno rápido. La aplicación de este instrumento es la principal diferencia con respecto a los siglos antecedentes, puesto que los análisis de pastas muestran que se siguen empleando los mismos desgrasantes en la elaboración de la vajilla y que, además, los recipientes siguen sometiéndose a una gradación idéntica. Los tipos formales continúan siendo prácticamente los mismos, si bien se observa ciertos cambios en su morfología. En cuanto a la decoración conviene resaltar el hecho de la existencia de algunos acabados que tradicionalmente se daban por desaparecidos para estas fechas tan tardías, caso de las líneas de pintura blanca, así como la identificación de varias piezas con acabados vidriados.

\section{BIBLIOGRAFÍA CITADA}

Albertí i Gubern, Santiago, El llibre d'ordinacions gremials dels ollers, gerrers i rajolers de Barcelona, "Butlletí Informatiu de Ceràmica" 36 (1988), pp. 22-26.

Albertí i Gubern, Santiago, Els origens gremials dels ceramistes de Barcelona, "Butlletí Informatiu de Ceràmica" 37 (1988), pp. 32-35.

Albertí i Gubern, Santiago, Notes sobre els rajolers de Barcelona a la Baixa Edat Mitjana, "Butlletí Informatiu de Ceràmica" 22 (1984), pp. 11-17.

Almagro Basch, Martín; Llubiá Munné, Luis, La cerámica de Teruel, Teruel, 1962.

Alonso Gregorio, Oscar, Propuesta de actuación para realización de sondeos arqueológicos en el yacimiento de "Los Corcales" (Valle de las Casa, Cebanico, León). Informe inédito depositado en el Servicio Territorial de Cultura de la Junta de Castilla y León, León, 2004.

Alonso Gregorio, Oscar, Trabajo de documentación arqueológica en el yacimiento de Los Corcales (Valle de las Casas, Cebanico, León). Informe inédito depositado en el Servicio Territorial de Cultura de la Junta de Castilla y León, León, 2005.

Alonso Ponga, José Luís, Historia antigua y medieval de la comarca de Los Oteros, León, Celarayn, D.L., 1981.

Álvarez Álvarez, César, Colección Documental del Archivo de la Catedral de León, XII (1351-1474), León, Centro de Estudios e Investigación "San Isidoro", 1995. 
Álvarez Álvarez, César, La ciudad de León en la Baja Edad Media. El espacio urbano, Madrid, Hullera Vasco-Leonesa, 1992.

Álvarez Álvarez, César, La Historia de León, Volumen II. Edad Media, León, Universidad de León, 1999.

Álvarez Delgado, Yasmina, Excavación en la villa bajomedieval de Moya, en I Congreso de Arqueología Medieval Española, Huesca, Asociación de Arqueología Medieval Española, 1985, t. IV, pp. 615-638.

Álvarez Ordás, José Carlos, Excavación arqueológica C/ Santa Marina c/v San Albito. Informe inédito depositado en el Servicio Territorial de Cultura de León, Junta de Castilla y León, León, 1997.

Álvaro Zamora, María Isabel, Cerámica aragonesa, Zaragoza, Librería General, 1976.

Amigues, François, La cerámica valenciana: sus técnicas de fabricación, en Spanish Medieval Ceramic in Spain and the British Isles, Oxford, Centre de Recherche Archeológique du CNRS, 1995, pp. 69-87.

Amigues, François, Premières aproches de la céramique commune des ateliers de Paterna (Valencia), en L'Obra aspra XIV-XV, Valencia, Casa de Velázquez, 1986, pp. 27-64.

Amigues, François; Mesqueda García, Mercedes, Tradición alfarera en Paterna: pasado y presente, in Fours de potiers et "testares" médievaux en Méditerranée Occidentale, Madrid, Casa de Velázquez, 1990, pp. 143-155.

Amigues, François; Mesqueda García, Mercedes, La céramique de Paterna. Ateliers et production, Bessiers, Museo de Bessiers, 1993.

Arce Martínez, Javier, Bárbaros y romanos en Hispania (400-507 A.D), Madrid, Centre de Recherche Archeológique du CNRS, 2005.

Arce Martínez, Javier, La trasformación de Hispania en época tardorromana: paisaje urbano, paisaje rural, en Actas del III Congreso de Estudios Medievales De la Antigüedad al Medievo. Siglos IV al VIII, León, Celarayn, D.L., 1993, pp. 227-249.

Argüello Menéndez, José Jorge, Un ejemplo de continuidad en la producción de cerámica desde la Edad Media al siglo XX: Faro (Asturies-España), "Olario: Estudos Arqueológicos, Históricos e Etnológicos" 2 (1998), pp. 93-100.

Atrián Jordán, Purificación, Hallazgo de cerámica medieval en Fortanete, "Teruel. Boletín Informativo de la Diputación Provincial" 41 (1985), pp. 23-25.

Bango Torviso, Isidro, Alta Edad Media. De la tradición hispano goda al románico, Madrid, Sílex Ediciones, 1989.

Bango Torviso, Isidro, Catedral de León. Desde la instauración de la diócesis hasta la magna obra de Manrique de Lara, en Actas del Congreso: La Catedral de León en la Edad Media, León, Universidad de León, 2004, pp. 45-57.

Bonnassie, Pierre, La organización del trabajo en Barcelona a fines del siglo XV, Barcelona, CSIC, 1975.

Boüard, Michel; Ollich, Immaculada; Riu, Manuel, Manual de Arqueología Medieval: de la prospección a la Historia, Barcelona, Editorial Teide, S.A., 1977.

Brando Castillo, Marianna; González Arpide, José Luís, Alfarería popular leonesa, León, Diputación de León, 1990.

Campomanes Alvaredo, Emilio; Muñoz Villarejo, Fernando, Memoria de la excavación arqueológica de la Plaza Mayor de León. Informe inédito depositado en el Servicio Territorial de Cultura de la Junta de Castilla y León, León, 2000.

Campos Sánchez-Bordona, María Dolores; Pereiras Fernández, María Luisa, Iglesia y ciudad, su papel en la configuración urbana de León: las Plazas de San Isidoro y Regla, León, Universidad de León, 2005. 
Carnero Felipe, Ramón Manuel, Historia de Pereruela de Sayago (Zamora) y su alfarería, Zamora, R. Carnero, 1998.

Carrero Santamaría, Eduardo, La arquitectura medieval al servicio de las necesidades litúrgicas: los conjuntos de iglesias, "Anales de historia del arte", $\mathrm{n}^{\circ}$ Extra 1 (2009), pp. 61-98.

Cavero Domínguez, Gregoria, Camino de Santiago, en La Historia de León, León, Universidad de León, 1999, pp. 101.

Córdoba de la Llave, Ricardo, Alfares y producción cerámica en Córdoba durante el siglo XV, "Ifigea" 2 (1985), pp. 195-202.

Córdoba de la Llave, Ricardo, Innovación técnica y desarrollo industrial en la Península Ibérica durante la Edad Media, en Actas de las I Jornadas sobre minería y tecnología en la Edad Media peninsular, León, Universidad de León, 1995, pp. 217-246.

Córdoba de la Llave, Ricardo, La industria medieval en Córdoba, Córdoba, 1990.

Córdoba de la Llave, Ricardo, Las técnicas preindustriales, "Historia de la Ciencia y de la Técnica en la Corona de Castilla", Valladolid, Junta de Castilla y León 2002, t. II, pp. 334-382.

Cortés Vázquez, Luis, La alfarería de Pereruela (Zamora), "Zephyrus" 5 (1954), pp. 141-163.

Cortés Vázquez, Luis, La alfarería femenina de Moveros (Zamora), "Zephyrus” 9 (1958), pp. 95-107.

Diago Hernando, Máximo, La industria y el comercio de productos textiles en Europa: siglos XI al XV, Madrid, Arco Libros, 1998.

Díaz Martínez, Pablo, El Parrochiale Suevum: organización eclesiástica, poder político y poblamiento en la Gallaecia Tardoantigua, en Homenaje a José María Blázquez, Madrid, Ediciones Clásicas, 1998, pp. 35-48.

Escó Sampériz, Carlos, Alfares, alfareros y producción cerámica en la Huesca medieval: siglos $X-X V$, "Bolskan: Revista de arqueología del Instituto de Estudios Altoaragoneses" 3 (1986), pp. 169-196.

Estepa Díez, Carlos, Estructura social de la ciudad de León (siglos XI-XIII), León, Centro de Estudios e Investigación "San Isidoro" 1977.

Estepa Díez, Carlos, La ciudad de León en la Alta Edad Media, en Real Colegiata de San Isidoro: relicario de la monarquía leonesa, León, Edilesa, 2007, pp. 12-27.

Estepa Díez, Carlos, León en los siglos XII-XII, en Historia de León, vol. II. El reino de León en la Edad Media, La Crónica, León, 1997, pp. 557-620

Fernández Catón, José María, Colección Documental del Archivo de la Catedral de León (775-1230) VI (1188-1230), León, Centro de Estudios e Investigación "San Isidoro", 1991.

Fernández Catón, José María, Colección Documental del Archivo de la Catedral de León IX (1269-1300), León, Centro de Estudios e Investigación "San Isidoro", 1994.

García Alén, Luciano, Notas para o estudio das región galego-portuguesas na producción da olería e cerámica, "Olario: Estudos Arqueológicos, Históricos e Etnológicos" 2 (1998), pp. 87-92.

García González, Juan José; Peterson, David; García Izquierdo, Iván; García Aragón, Luis, Introducción al conocimiento de la viaria romana de la cuenca del Duero a través de la documentación altomedieval, en Las técnicas y las construcciones de la ingeniería romana, Madrid, Colegio de Ingenieros Técnicos de Obras Públicas, 2010, pp. 135-163.

García Marcos, Victoriano, Excavación arqueológica del solar situado entre las plazas de San Alvito y Puerta Castillo y la calle Santa Marina, León. Informe 
inédito depositado en el Servicio Territorial de Cultura de León, Junta de Castilla y León, León, 2009.

García Marcos, Victoriano, Los campamentos de las legiones VI VICTRIX y VII GEMINA en León, en Arqueología Militar Romana en Europa, Valladolid, Universidad Internacional SEK, 2004, pp. 167-198.

Gomes Valera, Rosa; Gomes Valera, Mario, Quotidiano, religião e guerra santa, in Ribāt da Arrifana. Cultura material e espiritualidade, Aljezur, Associaçao de Defensa do Patrimonio Histórico e Arqueológico de Aljezur, 2007.

González Pérez, Primitivo, La cerámica preindustrial en la provincia de Valladolid, Valladolid, Diputación de Valladolid, 1989.

González Fernández, María Luz; Vidal Encinas, Julio, Recientes hallazgos sobre el campamento de la legio VII Gemina en León: la situación de los principia y la configuración de los latera praetorii, "Boletín del Seminario de Arte y Arqueología" 71 (2005), pp. 161-184.

Gutiérrez González, José Avelino, Las fuentes arqueológicas informadores del espacio urbano medieval: la ciudad de León como ejemplo, en El espacio urbano en la Europa Medieval, Logroño, Instituto de Estudios Riojano, 2006, pp. 77-145.

Gutiérrez González, José Avelino, Nuevos desarrollos en el estudio de las cerámicas medievales del norte de España. Una síntesis regional, en Spanish Medieval Ceramic in Spain and the British Isles. BAR International Series 610, Oxford, Centre de Recherche Arqueológique du CNRS, 1995, pp. 69-87.

Gutiérrez González, José Avelino; Benéitez González, Carmen, Aportaciones al repertorio cerámico bajomedieval castellano: las producciones de Valencia de don Juan, en La céramique médiévale en Méditerraneé. Actes du 6 congrés, Aix-en-Provence, Narration Éditions, 1997, pp. 539-548.

Gutiérrez González, José Avelino; Benéitez González, Carmen, Cerámica medieval en León, en La cerámica medieval en el norte y noroeste de la Península Ibérica, León, Universidad de León, 1989, pp. 211-260.

Gutiérrez González, José Avelino; Larrén Izquierdo, Hortensia; Benéitez González, Carmen; Turina Gómez, Araceli, Una producción mudéjar en Castilla y León: la jarrita Carenada, en Actes du 5ème colloque sur la cêramique médiévale en Méditerranée occidentale, Rabat, Institut National de Sciences, 1995 , pp. 316-324.

Gutiérrez González, José Avelino; Miguel Hernández, Fernando, Las cerámica altomedievales en León: producciones locales y andalusíes de Puerta Obispo, en VIII Congreso Internacional de Cerámica Medieval en el Mediterráneo, Ciudad Real, Asociación Española de Arqueología Medieval, 2009, pp. 447-461.

Ibáñez de Aldecoa, Esperanza, Cerámica tradicional asturiana, Gijón, TREA, 1998.

Igual Luis, David, Comercio e industria en las ciudades mediterráneas, "Revista d'historia medieval" 8 (1997), pp. 373-394.

Koper, Wulf, Guía de los alfares de España, Madrid, Ed. Nacional, 1981.

López Quiroga, Jorge, Entre la "villa" y la "aldea": arqueología de hábitat rural en Hispania (ss. V al VII), en Gallia e Hispania en el contexto de la presencia germánica (ss. V-VII): balance y perspectivas, Oxford, Centre de Recherche Arqueológique du CNRS, 2006, pp. 19-60.

Mansilla Reoyo, Demetrio, Panorama histórico-geográfico de la iglesia española (siglos VIII-XIV), en La iglesia en la España de los siglos VIII-XIV, Madrid, 1982, p. 21.

Marcos Blanco, Pedro, Legalidad y realidad de los exámenes gremiales en la ciudad de León en el siglo XVI, "Obradoiro de Historia Moderna" 8 (1999), pp. 135-168. 
Marchesi, Henry; Thiriot, Jacques; Vallauri, Lucy, El barrio de alfareros de Marsella em El siglo XIII: uma transferencia de tecnología, "Boletín de Arqueología Medieval" 6 (1995), pp. 35-43.

Marchesi, Henry; Thiriot, Jacques; Vallauri, Lucy, Le Faubourg des olliers de Marseille au XIIIème siècle, en Actes du 5ème colloque sur la cêramique médiévale en Méditerranée occidentale, Rabat, Institut National de Sciences, 1995, pp. 338-345.

Marchesi, Henry; Thiriot, Jacques; Vallauri, Lucy, Marseille, les ateliers de potiers du XIIIe s. et Le quartier Sainte-Barbe (Ve-XIIIe s.), París, Éditions de La Maison dês Sciences de l'Homme, 1997.

Martín López, María Encarna, Patrimonio cultural de San Isidoro de León. Documentos de los siglo X-XIII, León, Universidad de León, 1995.

Martínez Peñín, Raquel, Análisis de la producción y distribución de la cerámica leonesa durante la Edad Media, Oxford, Centre de Recherche Arqueológique du CNRS, 2011.

Martínez Peñín, Raquel, El alfar del barrio de Santa Cruz: un ejemplo de centro de producción alfarera bajomedieval en la ciudad de León, "Medievalismo: Boletín de la Sociedad Española de Estudios Medievales" 20 (en prensa).

Martínez Peñín, Raquel, El centro alfarero de Jiménez de Jamuz. Estudio histórico y etno-arqueológico, "Estudios Humanísticos" 5 (2006), pp. 309-332.

Martínez Peñín, Raquel, El mobiliario cerámico medieval de la basílica de Marialba de la Ribera (León), León, Ediciones Lobo Sapicus, 2008.

Martínez Peñín, Raquel, Estudio de la cerámica medieval del Castro de los Judíos, Puente Castro (León). Campaña de 1999, León, Universidad de León, 2008.

Mesqueda García, Mercedes, Alfareros medievales de Paterna, "Festes" 88 (1988), pp. 19-23.

Mesqueda García, Mercedes, La cerámica azul y dorada de Paterna: formas y decoraciones, en Actas das $1^{a}$ Jornadas de Cerâmica Medieval e Pós-medieval. Métodos e resultados para o seu estudo, Tondela, Cámara Municipal de Tondela, 1995, pp. 97-107.

Mesqueda García, Mercedes, La cerámica de Paterna en el siglo XIII, Paterna, Ayuntamiento de Paterna, 1989.

Mesqueda García, Mercedes, La cocción de cerámica en un horno medieval, en Actas del Seminario sobre la tecnología de la cocción cerámica, Alicante, Asociación de Ceranología, 1990, pp. 121-138.

Mesqueda García, Mercedes, Una terrisseria dels segles XIII i XIV, Paterna, Museu Municipal de Ceràmica, 1987.

Miguel Hernández, Fernando; García Marcos, Victoriano, Intervención arqueológica en el patio del Centro Cultural, "Nvmantia. Investigaciones Arqueológicas en Castilla y León” 4 (1993), pp. 175-206.

Mínguez Fernández, José María, Colección Diplomática del Monasterio de Sahagún (siglos IX y X), León, Centro de Estudios e Investigación “San Isidoro”, 1976.

Molera i Marimón, Judith; Vendrell Sanz, Marius, Caracterización tecnológica de las cerámicas producidas en el Testar del Molí (Paterna), en V Congreso Internacional de Cerámica Medieval del Mediterráneo Occidental, Rabat, Institut National de Sciences, 1995.

Morillo Cerdán, Ángel, Los campamentos romanos de Astorga y León, "Espacio, tiempo y forma. Serie II, Historia Antigua” 16 (2003), pp. 83-110.

Navarro Espinach, Germán, La industria textil en Zaragoza antes de 1500, "Anuario de Estudios Medievales" 38/2 (2008), pp. 673-705.

Oliva Ferres, Hipólito Rafael, La industria textil en Tierra de Campos a finales de la Edad Media, "Studia Historica. Historia Medieval" 18-19 (2001), pp. 225-251. 
Ortega Ortega, Julian, Cerámica y feudalismo: una aproximación a la cerámica medieval en Teruel, "Kalathos: Revista del seminario de arqueología y etnología turolense" 15 (1996), pp. 111-141.

Ortega Ortega, Julian, El contexto historiográfico de la "Cerámica de Teruel": algunas reflexiones sobre las producciones medievales, "Kalathos: Revista del seminario de arqueología y etnología turolense" 15 (1996), pp. 79-110.

Ortega Ortega, Julian, Operis Terra Turolii. La cerámica bajomedieval en Teruel, Teruel, Diputación Provincial de Teruel, 2002.

Ortega Ortega, Julian; Gutiérrez González, Francisco Javier, La cerámica medieval desde el lado de la demanda. Sobre comercio y consumo cerámico en Zaragoza Bajomedieval: el ejemplo del Teatro Fleta, "Kalathos: Revista del seminario de arqueología y etnología turolense" 24-25 (2006), pp. 397-421.

Padilla la Puente, José Ignacio, Adaptación al medio y transformación artesanal: balance actual de las investigaciones acerca del alfar medieval de Cabrera d'Anoia, "Boletín de Arqueología Medieval" 14 (2010), pp. 259-294.

Padilla la Puente, José Ignacio; Vila i Carabasa, Josep Maria, El artesanado medieval de la cerámica en el nordeste peninsuar: una aproximación a las fuentes escritas, en Actas das $1^{a}$ Jornadas de Cerâmica Medieval e Pós-Medieval, Tondela, Câmara Municipal de Tondela, 1995, pp. 249-261.

Padilla la Puente, José Ignacio; Vila i Carabasa, Josep Maria, El tester 347-B de Cabrera d'Anoia. Anàlisi d'una fase de la producció d'aquest centre artesanal, en Cerámica medieval catalana: el monument. Document, Barcelona, Diputación de Barcelona, 1997, pp. 143-158.

Padilla la Puente, José Ignacio; Vila i Carabasa, Josep Maria, Els oficis terrissers a la Barcelona de l'Edat Mitjana, en Del rebost a la taula. Cuina i menjar a la Barcelona gòtica, Barcelona, El Medol, 1994, pp. 63-70.

Padilla la Puente, José Ignacio; Vila i Carabasa, Josep Maria, Últimas intervenciones en el alfar medieval de Cabrera d'Anoia. Barcelona, en II Jornadas de Cerámica Medieval e Pós Medieval. Métodos e resultados, Tondela, Câmara Municipal de Tondela, 1998, pp. 91-99.

Pérez Álvarez, María José, Mortalité et hygiène dans la ville de León au cours de l'époque moderne, "Annales de Bretagne et des Pays de l'ouest" 116/2 (2009), pp. 55-79.

Picon, Maurice; Thiriot, Jacques; Abraços, Helder; Diogo, José Manuel, Estudo em laboratorio e observação etnoarqueológica das cerámicas negras portuguesas, en Actas das $1^{a}$ Jornadas de Cerâmica Medieval e Pós-medieval. Métodos e resultados para seu estudo, Tondela, Câmara Municipal de Tondela, 1995, pp. 189-207.

Represa Rodríguez, Armando, Evolución urbana de León en los siglos XI-XIII, “Archivos Leoneses" 45-46 (1969), pp. 243-282.

Riu de Martín, María Carmen, Algunos aspectos de la producción y comercio de la cerámica barcelonesa de los siglos XV-XVI, en VIII Congreso Internacional de Cerámica Medieval en el Mediterráneo, Ciudad Real, Asociación Española de Arqueología Medieval, 2009, t. I, pp. 135-140.

Riu de Martín, María Carmen, Ceramistas barceloneses del siglo XIV, "Boletín de Arqueología Medieval" 12 (2006), pp. 191-206.

Riu de Martín, María Carmen, El treball artesà a Barcelona els segles XIV al XVI segons les ordenacions gremials: la cerámica, en VI Congrés Internacional d'Història Local de Catalunya: Sociabilitat i àmbit local, Barcelona, L'Avenç, 2003, pp. 9-19.

Riu Martín, María Carmen, Vida cotidiana de los ceramistas y vidrieros barceloneses, "Anuario de Estudios Medievales" 34/1 (2004), pp. 307-355. 
Roselló Bordoy, Guillermo, El ajuar de las casas andalusíes, Málaga, Editorial Sarriá, 2002.

Rubio Pérez, Laureano Manuel, Historia de León. Edad Moderna, vol. 3, León, Universidad de León, 1999.

Rubio Pérez, Laureano Manuel, Ordenanzas de León, León, Universidad de León, 1996.

Ruíz Asencio, José Manuel, Colección Documental del Archivo de la Catedral de León (775-1230), III (986-1031), León, Centro de Estudios e Investigación "San Isidoro", 1987.

Ruíz Asencio, José Manuel, Colección Documental del Archivo de la Catedral de León (775-1230), IV (1032-1109), León, Centro de Estudios e Investigación "San Isidoro", 1990.

Sánchez Badiola, Juan José, La configuración de un sistema de poblamiento y organización del espacio: el territorio de León (siglos IX-XI), León, Universidad de León, 2002.

Sempere, Emili, Rutas a los alfares: España-Portugal, Barcelona, 1982.

Valdés Fernández, Manuel; Cosmen Alonso, Concha; Herráez Ortega, María Victoria, Una historia arquitectónica de la catedral de León, León, S. García, 1994.

Valdés Fernández, Manuel; Herráez Ortega, María Victoria; Cosmen Alonso, Concha, El arte gótico en la provincia de León, León, Universidad de León, 2001.

Vidal Encinas, Julio, Caminos y puentes antiguos en la provincia de León: problemas de identificación y conservación desde la arqueología, en Caminos históricos en León (en prensa).

Vila i Carabasa, Josep Maria, Política municipal sobre la producció de cèramica $i$ l'organització corporativa dels terrissers a Barcelona, segles XIV-XVI, “Arqueología Medieval” 1 (2005), pp. 104-126.

Vila i Carabasa, Josep Maria; Padilla la Puente, Jose Ignacio; Hernando Delgado, Josep, Cerámica de almacenamiento y transporte en el Mediterráneo Norooccidental. Siglos XIV-XV, en La céramique médiévale en Méditerranée. Actes du 6 congrès, Aix-en-Provence, Narration Éditions, 1997, pp. 559-562.

Fecha de recepción del artículo: septiembre 2011

Fecha de aceptación y versión final: octubre 2011 